\title{
Intranasal Immunization With 0-2'-Hydroxypropyl Trimethyl Ammonium Chloride Chitosan Nanoparticles Loaded With Newcastle Disease Virus DNA Vaccine Enhance Mucosal Immune Response in Chickens
}

kai zhao ( $\nabla$ zybin395@126.com )

Taizhou University

\section{Beini Sun}

Heilongjiang University

Ci Shi

Heilongjiang University

\section{Yanwei Sun}

Heilongjiang University

Zheng Jin

Heilongjiang University

Gaowei Hu

Taizhou University

\section{Research}

Keywords: Newcastle disease virus, DNA vaccine, 0-2'-Hydroxypropyl trimethyl ammonium chloride 38 chitosan nanoparticles, intranasal delivery, mucosal immunity

Posted Date: June 10th, 2021

DOI: https://doi.org/10.21203/rs.3.rs-589444/v1

License: (c) (i) This work is licensed under a Creative Commons Attribution 4.0 International License. Read Full License

Version of Record: A version of this preprint was published at Journal of Nanobiotechnology on August 11th, 2021. See the published version at https://doi.org/10.1186/s12951-021-00983-5. 
Intranasal immunization with $\boldsymbol{O}-\mathbf{2}^{\prime}$-Hydroxypropyl trimethyl ammonium chloride chitosan

nanoparticles loaded with Newcastle disease virus DNA vaccine enhance mucosal immune

\section{response in chickens}

Kai Zhao ${ }^{1,2,3,{ }^{*}, \text { Beini Sun }}{ }^{2}$, Ci Shi ${ }^{2}$, Yanwei Sun ${ }^{2}$, Zheng $\mathrm{Jin}^{4}$, Gaowei Hu ${ }^{1}$

${ }^{1}$ Institute of Nanobiomaterials and Immunology, School of Life Science, Taizhou University, Taizhou

\section{0, China}

${ }^{2}$ Engineering Research Center of Agricultural Microbiology Technology, Ministry of Education, Heilongjiang University, Harbin 150080, China

${ }^{3}$ Key Laboratory of Microbiology, College of Heilongjiang Province, School of Life Science, Heilongjiang University, Harbin 150080, China

${ }^{4}$ Key Laboratory of Chemical Engineering Process and Technology for High-efficiency Conversion, College of Chemistry and Material Sciences, Heilongjiang University, Harbin, 150080, China

Running title: O-2'-HACC nanoparticles as adjuvant and delivery carrier for DNA vaccine

*Correspondence: Kai Zhao, Tel: +86 576 88660338, E-mail: zybin395@126.com 
Abstract:

Background: There is a great interest to develop strategies for enhancing antigen delivery to mucosal

21 immune system as well as to identify mucosal active immunostimulating agents. To elevate the potential of $O-2^{\prime}$-Hydroxypropyl trimethyl ammonium chloride chitosan (O-2'-HACC) nanoparticles as adjuvant and mucosal immune delivery carrier for DNA vaccine, we prepared the O-2'-HACC nanoparticles loaded with Newcastle disease virus F gene plasmid DNA with C3d6 molecular adjuvant (O-2'-HACC/pFDNA). Results: The O-2'-HACC/pFDNA had regular spherical morphology with a particle size of $202.3 \pm 0.52$ $\mathrm{nm}$, zeta potential of $50.8 \pm 8.21 \mathrm{mV}$, encapsulation efficiency of $90.74 \pm 1.10 \%$, and loading capacity of $49.84 \pm 1.20 \%$. The plasmid DNA could be sustainably released from the O-2'-HACC/pFDNA after an initial burst release. Intranasal vaccination of chickens immunized with O-2'-HACC/pFDNA not only induced higher anti-NDV IgG and sIgA antibody titers, but also significantly promoted lymphocyte proliferation and produced the higher levels of IL-2, IL-4, IFN- $\gamma$, CD4+ and CD8+ T lymphocytes than the NDV commercial attenuated live vaccine. Intranasal delivery of the O-2'-HACC/pFDNA enhanced humoral, cellular and mucosal immune responses, and protected chickens from the infection of highly virulent NDV than intramuscular delivery.

34 Conclusions: This study indicated that the O-2'-HACC nanoparticles could be used as vaccine adjuvant and delivery system for mucosal immunity and have an immense application promise. chitosan nanoparticles; intranasal delivery; mucosal immunity. 


\section{Background}

Mucosal immune system is an important part of the body's entire immune network, and it plays an active and important role in fighting infection [1]. Mucosal immune response can be improved by selecting the optimal immunization route, vaccine adjuvant and delivery system etc. [2]. Mucosal vaccination not only induces a corresponding immune response at the site of inoculation, but also produces a corresponding immune response in other distant mucosal tissues. Nasal mucosa is the first part to contact the inhaled antigen, nasal mucosal immunity can induce stronger mucosal immune response and higher systemic immune responses in the distant mucosal tissues [3, 4], thus intranasal vaccination is considered to be a more favorable mucosal immune route.

Newcastle disease (ND) is an acute and highly contagious disease caused by Newcastle disease virus (NDV) $[4,5]$. The most economical and effective way to prevent ND is vaccination [6]. Compared to traditional vaccine, DNA vaccine has great advantages and potential, DNA vaccine has higher safety, better genetic stability and immune effect, simple production, convenient storage and transportation etc. However, the administration of DNA vaccine is intramuscular injection, and several studies have shown that DNA vaccines don't effectively delivery antigen to antigen-presenting cells (APCs) after intramuscular injection, therefore, this leads to a strong immune response that can't be induced [7, 8]. Additionally, DNA vaccine has also been limited in clinical applications due to intramuscular injection, high dose, low bioavailability and immunogenicity [9]. Various strategies have been considered for enhancing mucosal immune response by using the suitable vaccine adjuvant, specific targeting of ligands, delivery system etc. Suitable vaccine adjuvant and delivery system in DNA vaccines can improve the immunogenicity, induce stronger immune responses and reduce the dosage and production cost of vaccine in populations responding poorly to vaccination $[10,11]$. 
64 Although viral vector has many advantages for the delivery of plasmid DNA, one of the most important

65 issues is able to ensure that plasmid DNA is not degraded by lysosomes during transport to the host cell.

66 And the viral vector must be non-pathogenic to the human body and will not cause proliferation and spread

67 in the environment, high titer production and high immunogenicity safety [12]. Compared to viral vector,

68

69

70

non-viral vector has some advantages, including no infectivity, low immunogenic response, safety, high gene capacity, stability, no carrier capacity limitation, and are easy to prepare in large quantities $[13,14]$.

Non-viral gene delivery system generally consists of the naked DNA delivery, lipid-based delivery and polymer-based delivery etc. Cationic polymer, which electrostatically interact with plasmid DNA to neutralize its negative charge and condense the plasmid DNA into nanosized particles, is generally served as gene delivery systems. Cationic polymer nanoparticles can protect the plasmid DNA from enzymatic degradation and facilitate cellular uptake. Intramuscularly administered polyvinyl alcohol/plasmid DNA formulation resulted in a significant increasing in the number and distribution of the reporter-gene expressing cells in rat, compared to naked plasmid DNA [15]. Biodegradable, non-antigenic polymer-based microspheres/nanoparticles have many advantages as vaccine adjuvant and delivery system.

Our previous studies have shown that cellular, humoral and mucosal immune responses can be elicited to antigens encapsulated in, or conjugated onto polymer-based microspheres/nanoparticles [16, 17].

Since the particle size of nanoparticles is comparable to that of the pathogen, nanoparticles can pass through the interstitial space and capillaries to reach a site that is difficult to administer, and has the many advantages, including controlling drug release, protecting drug from degradation or leakage, and targeting administration etc., thus, nanoparticles can significantly improve the delivery efficiency of plasmid DNA. At present, biodegradable nanomaterials for preparing polymer-based nanoparticles mainly include 
chitosan and its derivatives, hyaluronic acid and sodium alginate etc. Among them, chitosan and its nanoparticles have broadly used as drug/vaccine delivery vector due to their safety, non-toxicity, biocompatibility, biodegradability and sustained release in industrial and technological applications [18, 19]. However, the poor solubility of chitosan greatly restricts the application scopes and fields of chitosan.

One of strategies to improve the solubility of chitosan is to modify the structure of chitosan by the addition of hydrophilic functional groups [20]. Therefore, water soluble chitosan derivatives-based nanoparticles as vaccine adjuvant and delivery vector have become novel vaccine/drug delivery system. We have synthesized the water soluble $O-2^{\prime}$-Hydroxypropyl trimethyl ammonium chloride chitosan (O-2'-HACC) [21], to prove the ability of O-2'-HACC nanoparticles as DNA vaccine adjuvant and delivery vector to reach sustained release and desired mucosal immunity, we prepared the O-2'-HACC nanoparticles loaded with Newcastle disease virus F gene plasmid DNA by using the polyelectrolyte complex method, and the intranasal delivery of nano vaccine was investigated to demonstrate the potential for mucosal immunity.

\section{Results}

\section{Characterization of the O-2'-HACC/pFDNA}

O-2'-HACC/pFDNA was regular spherical morphology, smooth surface and good dispersion (Fig.

1A). The average particle size of the nanoparticles was $202.3 \pm 0.52 \mathrm{~nm}$ (Fig. 1B), Zeta potential was

$50.8 \pm 8.21 \mathrm{mV}$ (Fig. 1C), EE was $92.27 \pm 1.48 \%$, and LC was $50.75 \pm 1.35 \%$.
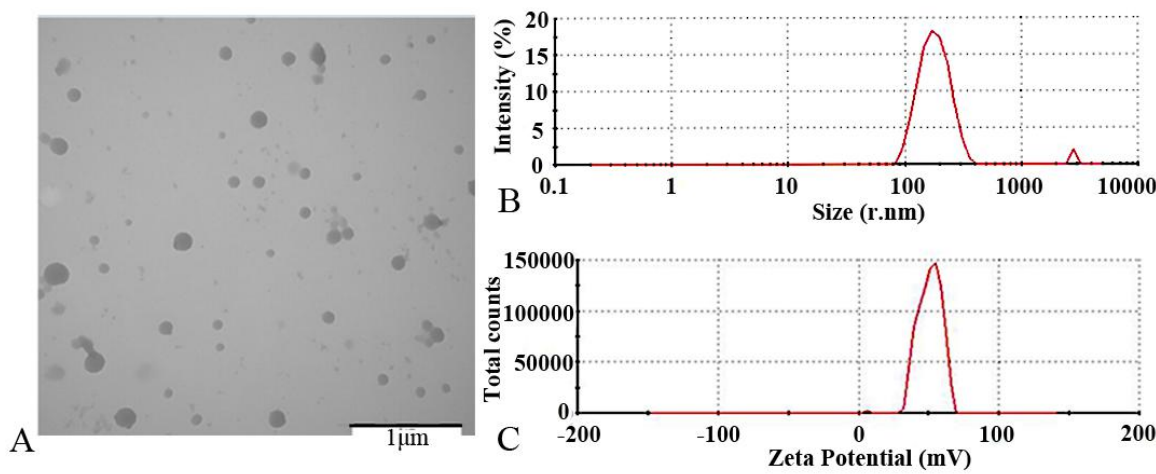


\section{DNase I protection assay}
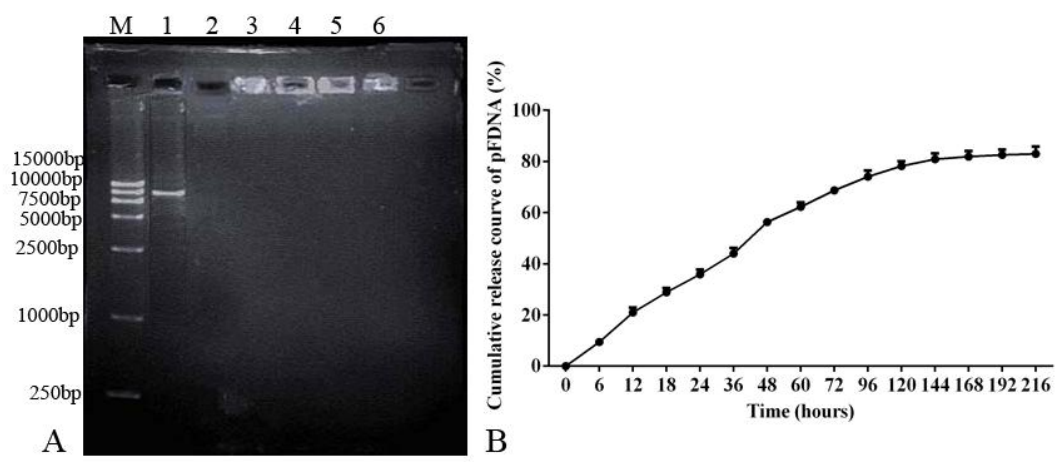

111 Fig. 2. Stability and in vitro release analysis of the plasmid pVAX I -F(o)-C3d6 after encapsulation in the in PBS solution $(\mathrm{pH}=7.4)$. Data are presented as the mean $\pm \mathrm{SD}$ deviation $(\mathrm{n}=3)$. 
serve as delivery vector for the sustained and slow release of DNA vaccine.

\section{Safety of the O-2'-HACC/PFDNA}

The survival rate of chicken embryo fibroblasts in O-2'-HACC/pFDNA was $90.48 \pm 2.14 \%$, and no significant change in cell morphology was observed compared to control cells $(P>0.05)$. In vivo cytotoxicity analysis showed that the chickens immunized with the O-2'-HACC/pFDNA i.m. or i.n. were normal in feeding, drinking, mental state, body weight and inoculation sites, and there was no morbidity and mortality, indicating that the O-2'-HACC/pFDNA was safe. Histopathological analysis showed that glandular stomach, duodenum, quadriceps femoris and nasal mucosa were intact and no lesions as shown in Fig. 3A. These findings indicate that the O-2'-HACC NPs has little cytotoxicity as delivery vector, but has higher safety level by administration intranasal.

\section{Stability of the O-2'-HACC/pFDNA}

The O-2'-HACC/pFDNA was milky white powder, loose and spongy. The morphology of the nanoparticles didn't change after stored at room temperature, $4^{\circ} \mathrm{C}$ and $-20^{\circ} \mathrm{C}$ for three weeks, but there was slightly shrinking at $37^{\circ} \mathrm{C}$ after stored for three weeks, indicating that the O-2'-HACC/pFDNA had good storage stability and could be stored for a long period of time at the room temperature. As seen from Fig. 3B, after the O-2'-HACC/pFDNA stored for two and three months at room temperature, serum IgG antibody titers in chickens of the O-2'-HACC/pFDNA i.m. was not significantly different from the newly prepared O-2'-HACC/pFDNA i.m. $(P>0.05)$.

\section{In vitro expression of the O-2'-HACC/pFDNA}

Fluorescence was detected in the O-2'-HACC/pFDNA and pVAXI-F(o)-C3d6 groups (Fig. 3C). No fluorescence was detected in the O-2'-HACC NPs and 293T cells groups. These results indicated that the plasmid DNA can be efficiently encapsulated by the O-2'-HACC NPs and expressed in vitro, indicating 

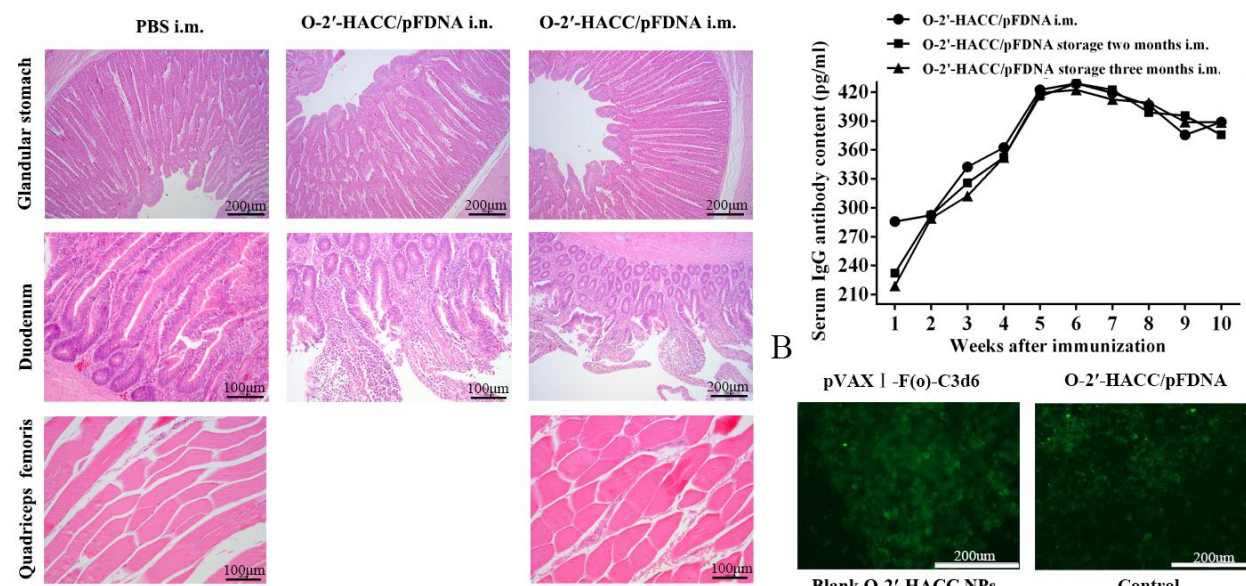

O-2'-HACC/PFDNA
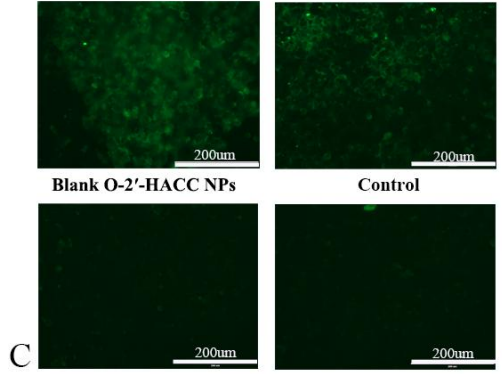
Control
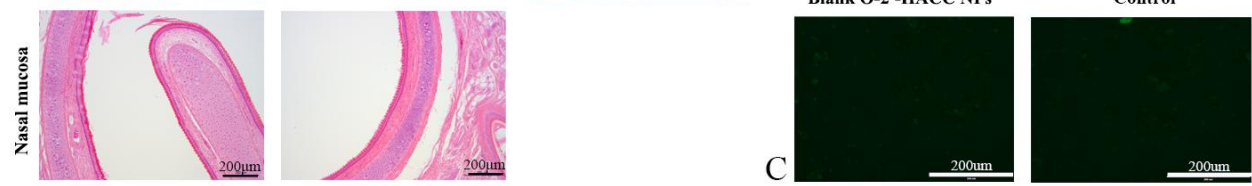

Fig. 3. Safety analysis, in vitro fluorescence expression and storage stability of the O-2'-HACC/pFDNA.

(A) Histopathological analyses of glandular stomach, duodenum, quadriceps femoris and nasal mucosa; (B)

\section{Intranasal immune response}

As shown in Fig. 4A, at fifth week post the immunization, the serum antibody titers were significantly 
IgA antibody titers in chickens immunized with the O-2'-HACC/pFDNA i.n. were significantly increased in serum (Fig. 4B), tracheal fluid (Fig. 4C), bile (Fig. 4D) and harderian gland (Fig. 4E) $(P<0.01)$, and the time of IgA antibody secretion was also longer than the other groups $(P<0.01)$. These results indicated that the $\mathrm{O}-2^{\prime}-\mathrm{HACC} / \mathrm{pFDNA}$ i.n. induced higher IgA antibody secretion than the O-2'-HACC/pFDNA i.m, pVAX I -F(o)-C3d6 i.m. and attenuated live ND vaccine i.m. $(P<0.01)$. In addition, IgA antibody titers in O-2'-HACC/pFDNA i.n. was higher than that of the O-2'-HACC/pFDNA i.m, pVAXI-F(o)-C3d6 i.m. and attenuated live ND vaccine i.m. $(P<0.01)$. The period of immunization protection in O-2'-HACC/pFDNA i.n. was longer, because the O-2'-HACC increased the contact time of antigen with the mucosal surface, thus effectively improved the antigen-associated lymphoid tissue, induced higher secretion levels of $\operatorname{IgG}$ and $\operatorname{IgA}$ in the body, indicating that the O-2'-HACC/pFDNA produced stonger humoral immune and mucosal immune responses.
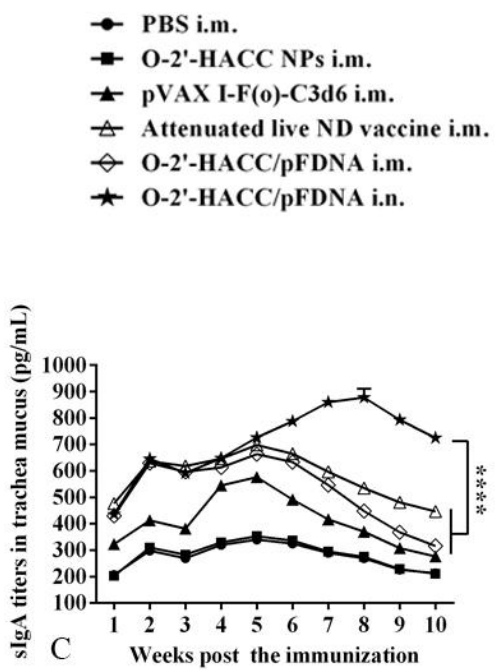
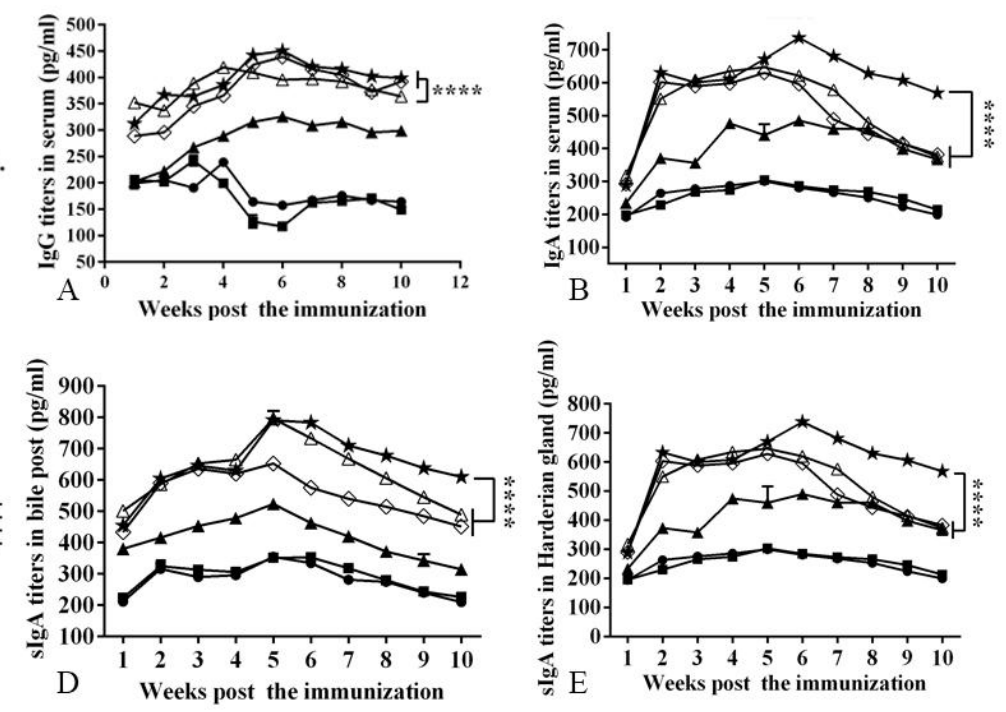

Fig. 4. IgG and IgA antibody titers in serum (A, B), trachea mucus (C), bile (D), and harderian gland (E) 
181 was significantly higher than the O-2'-HACC/pFDNA i.m. $(P<0.05)$, which showed that the

185 the more lymphocytes proliferation and triggered stronger specific immune response.

186 Table 1 Analysis of lymphocyte proliferation in SPF chickens immunized with the O-2'-HACC/pFDNA i.m. and PBS i.m.

\begin{tabular}{|c|c|c|c|c|c|c|c|c|c|c|}
\hline \multirow{2}{*}{ Groups } & \multicolumn{10}{|c|}{ Weeks post the immunization } \\
\hline & 1 & 2 & 3 & 4 & 5 & 6 & 7 & 8 & 9 & 10 \\
\hline O-2'-HACC/pFDNA & 0.604 & 2.490 & 3.213 & 4.141 & 4.410 & 4.384 & 4.360 & 3.930 & 3.228 & $2.983 \pm 0$ \\
\hline i.n. & $\pm 0.014^{\mathrm{a}}$ & $\pm 0.038^{\mathrm{a}}$ & $\pm 0.018^{\mathrm{a}}$ & $\pm 0.012^{\mathrm{a}}$ & $\pm 0.011^{\mathrm{a}}$ & $\pm 0.056^{\mathrm{a}}$ & $\pm 0.045^{\mathrm{a}}$ & $\pm 0.054^{\mathrm{a}}$ & $\pm 0.042^{\mathrm{a}}$ & $.034^{\mathrm{a}}$ \\
\hline O-2'-HACC/pFDNA & 0.568 & 2.350 & 3.086 & 3.705 & 4.145 & 3.756 & 2.668 & 2.345 & 1.986 & $1.639 \pm 0$ \\
\hline i.m. & $\pm 0.003^{\mathrm{a}}$ & $\pm 0.046^{\mathrm{a}}$ & $\pm 0.047^{\mathrm{b}}$ & $\pm 0.022^{\mathrm{b}}$ & $\pm 0.110^{\mathrm{b}}$ & $\pm 0.108^{\mathrm{b}}$ & $\pm 0.032^{\mathrm{b}}$ & $\pm 0.049^{\mathrm{b}}$ & $\pm 0.019^{\mathrm{b}}$ & $.010^{\mathrm{b}}$ \\
\hline Attenuated live ND & $0.674 \pm$ & 2.660 & 3.368 & $4.192 \pm 0$ & 4.488 & 4.422 & 4.439 & 3.989 & 3.162 & $2.970 \pm 0$ \\
\hline vaccine i.m. & $0.008^{\mathrm{a}}$ & $\pm 0.015^{\mathrm{a}}$ & $\pm 0.040^{\mathrm{a}}$ & $.016^{\mathrm{a}}$ & $\pm 0.015^{\mathrm{a}}$ & $\pm 0.012^{\mathrm{a}}$ & $\pm 0.078^{\mathrm{a}}$ & $\pm 0.014^{\mathrm{a}}$ & $\pm 0.055^{\mathrm{a}}$ & $.031^{\mathrm{a}}$ \\
\hline pVAX I -F(o)-C3d6 & 0.435 & 2.124 & 2.779 & 3.148 & 3.598 & 3.278 & 2.440 & 1.897 & 1.810 & $1.683 \pm 0$ \\
\hline i.m. & $\pm 0.018^{\mathrm{b}}$ & $\pm 0.006^{\mathrm{b}}$ & $\pm 0.017^{\mathfrak{c}}$ & $\pm 0.047^{\mathrm{c}}$ & $\pm 0.013^{\mathrm{c}}$ & $\pm 0.017^{\mathrm{c}}$ & $\pm 0.005^{\mathrm{c}}$ & $\pm 0.009^{\mathrm{c}}$ & $\pm 0.010^{\mathrm{c}}$ & $.011^{\mathrm{b}}$ \\
\hline \multirow{2}{*}{ O-2'-HACC NPs i.m. } & $0.402 \pm$ & 1.058 & 1.968 & 2.156 & 2.256 & 2.171 & 2.144 & 2.023 & 1.972 & $1.581 \pm 0$ \\
\hline & $0.004^{\mathrm{b}}$ & $\pm 0.060^{\mathrm{c}}$ & $\pm 0.019^{\mathrm{d}}$ & $\pm 0.011^{\mathrm{d}}$ & $\pm 0.038^{\mathrm{d}}$ & $\pm 0.012^{\mathrm{d}}$ & $\pm 0.010^{\mathrm{d}}$ & $\pm 0.040^{\mathrm{d}}$ & $\pm 0.017^{\mathrm{b}}$ & $.037^{\mathrm{c}}$ \\
\hline \multirow{2}{*}{ PBS i.m. } & 0.306 & 1.301 & 1.924 & 2.085 & 2.117 & 1.905 & 1.879 & 1.839 & 1.702 & $1.459 \pm 0$ \\
\hline & $\pm 0.010^{\mathrm{c}}$ & $\pm 0.006^{\mathrm{d}}$ & $\pm 0.017^{\mathrm{d}}$ & $\pm 0.018^{\mathrm{d}}$ & $\pm 0.007^{\mathrm{e}}$ & $\pm 0.009^{\mathrm{e}}$ & $\pm 0.019^{\mathrm{e}}$ & $\pm 0.016^{\mathrm{e}}$ & $\pm 0.008^{\mathrm{d}}$ & $.022^{\mathrm{d}}$ \\
\hline
\end{tabular}

189 Notes: Values represent mean $\pm \mathrm{SD}(\mathrm{n}=3)$. Values within the same column with the different lower case

190 letter $(\mathrm{a}-\mathrm{e})$ in the superscript indicate statistically significant differences $(P<0.05)$. 

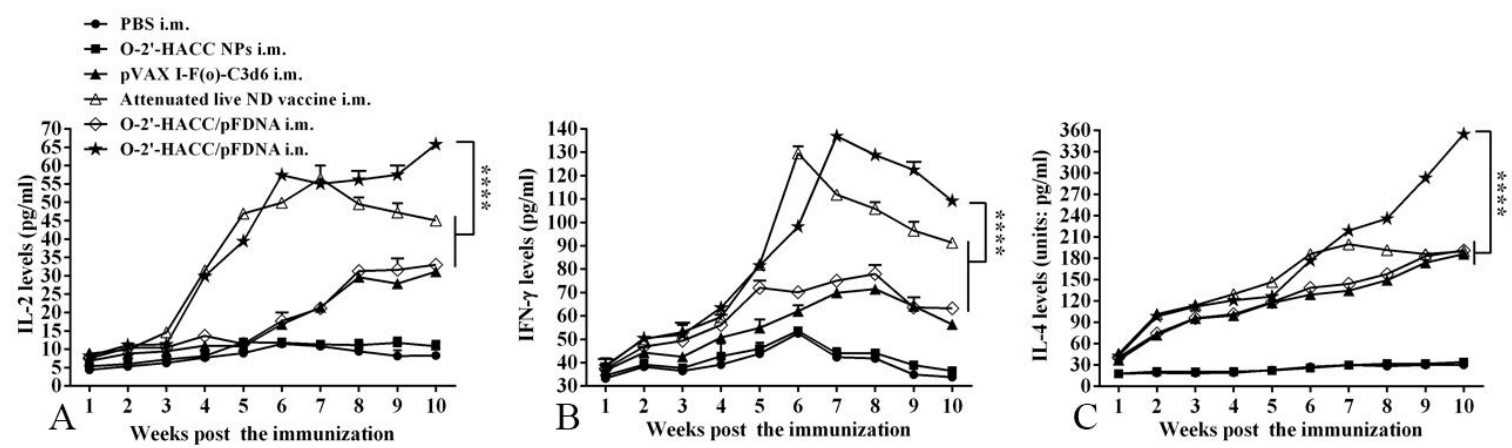

Fig. 5. IL-2 (A), IL-4 (B), and IFN- $\gamma$ (C) levels in the supernatant of splenocytes harvested from the SPF

chickens immunized with the PBS i.m., O-2'-HACC NPs i.m., pVAX I-F(o)-C3d6 i.m., attenuated live ND

supernatant were analyzed in a chicken IFN- $\gamma$, IL-2, and IL-4 enzyme-linked immunosorbent assay.

ND vaccine i.m. group were significantly higher than that in PBS, O-2'-HACC/pFDNA i.n. and 

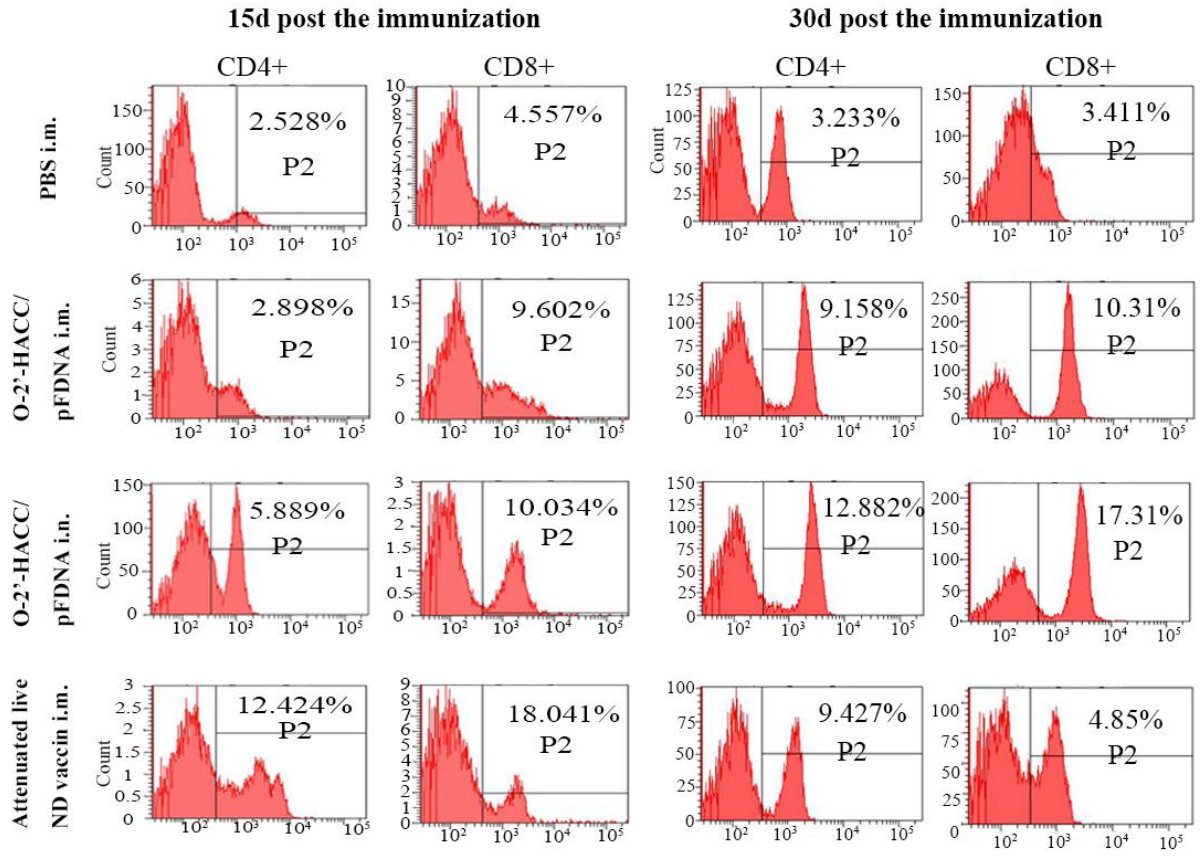

Fig. 6. Levels of CD4+ and CD8+ T lymphocytes in peripheral blood post 15 days and 30 days after the immunization.

Immune protective efficacy

Serum HI antibody titers

Anti-NDV antibody titers in chickens immunized with the O-2'-HACC/pFDNA i.n., and the level of IgG antibody in the O-2'-HACC/pFDNA i.n. was slightly higher than that in the O-2'-HACC/pFDNA i.m., but the difference between the two groups was not significant $(P>0.05)$. IgG antibody titers in the O-2'-HACC/pFDNA i.n. and i.m. were higher than those of pVAX I -F(o)-C3d6 i.m. and attenuated live ND vaccine i.m. groups $(P<0.05)$. Serum IgG antibody levels in the O-2'-HACC/pFDNA i.n. decreased slowly in the 3-5 weeks after challenge and maintained a higher level

(Fig. 7A).

\section{Changes of cytokine levels after challenge}

At the second week after challenge, IL-2 content in serum in the attenuated live ND vaccine i.m. 
reached the highest value (Fig. 7B), but there was no significant different between the attenuated live ND vaccine i.m. and O-2'-HACC/pFDNA i.n. $(P<0.05)$. At the third week after challenge, IL-2 content in the groups until the fifth week $(P<0.05)$ (Fig. 7B). i.m. group $(P<0.05)($ Fig. 7C). after challenge $(P<0.01)$, and IFN- $\gamma$ levels in the O-2'-HACC/pFDNA i.n. continued to maintain high
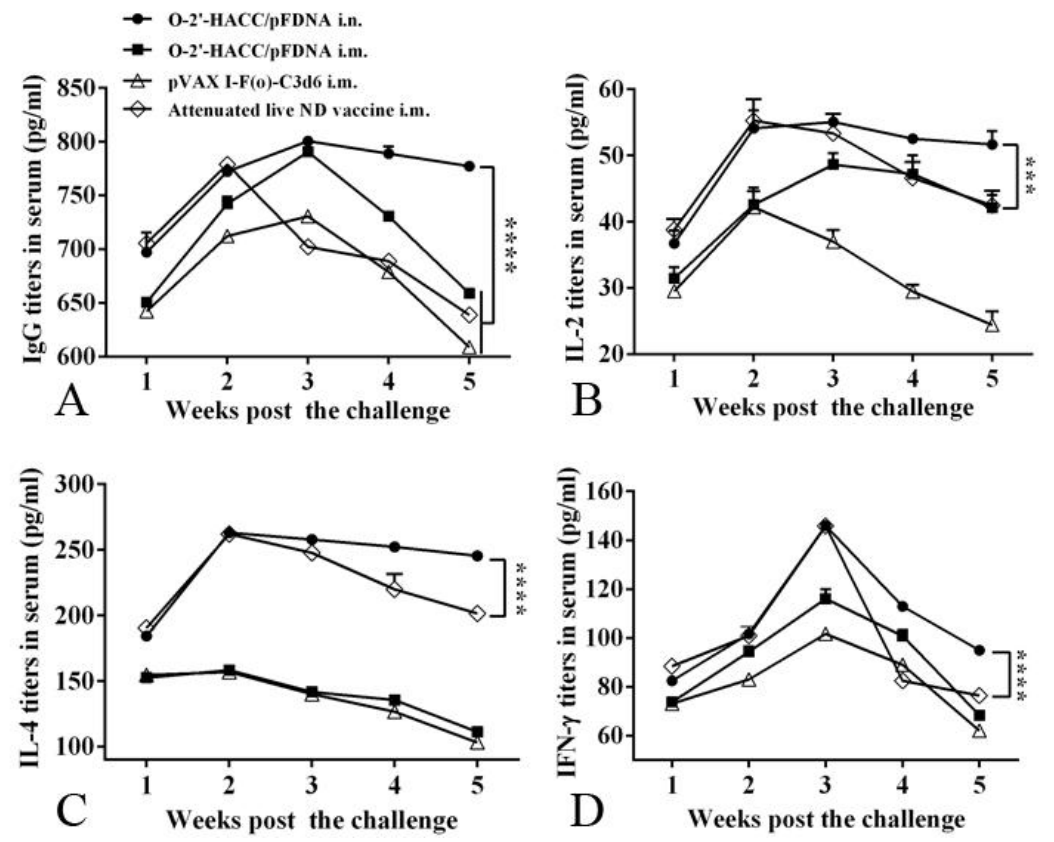

Fig. 7. Serum IgG antibody titers (A) and IL-2 (B), IL-4 (C), IFN- $\gamma$ (D) levels in the supernatant of 
Protective effect

Chickens in PBS and O-2'-HACC NPs groups died within 4-7 days after challenge. After challenge,

245 two chickens immunized with the pVAX I -F(o)-C3d6 i.m. died, chickens in the attenuated live ND

246 vaccine i.m., O-2'-HACC/pFDNA i.m. and the O-2'-HACC/pFDNA i.n. didn't die (Table 2). All the dead

247 chickens showed the typical ND pathological changes, such as the severe congestion of intestinal wall and

248 intestinal mucosa, and small bleeding spots on the surface of glandular stomach. However, these lesions

249 didn't appear in chickens immunized with the O-2'-HACC/pFDNA i.m., i.n. and attenuated live ND

250 vaccine i.m. (Fig. 8).

251 Table 2 Protection efficiency of the immunized SPF chickens after challenged with the highly virulent

252 NDV strain F48E9

\begin{tabular}{cccc}
\hline Groups & $\begin{array}{c}\text { Number of dead chickens/Total } \\
\text { number of chickens }\end{array}$ & Mortality (\%) & Protection (\%) \\
\hline O-2'-HACC/pFDNA i.n. & $0 / 7$ & 0 & 100 \\
O-2'-HACC/pFDNA i.m. & $0 / 7$ & 0 & 100 \\
Attenuated live ND vaccine i.m. & $0 / 7$ & 0 & 100 \\
pVAX I -F(o)-C3d6 i.m. & $2 / 7$ & 28.6 & 71.4 \\
O-2'-HACC NPs i.m. & $7 / 7$ & 100 & 0 \\
PBS i.m. & $7 / 7$ & 100 & 0 \\
\hline
\end{tabular}



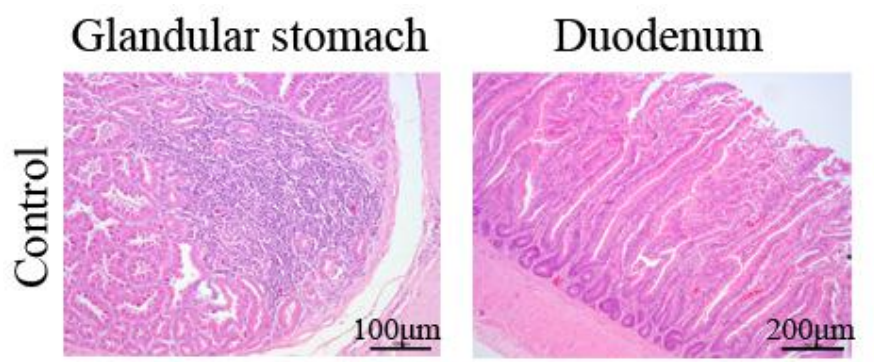

Myocardium
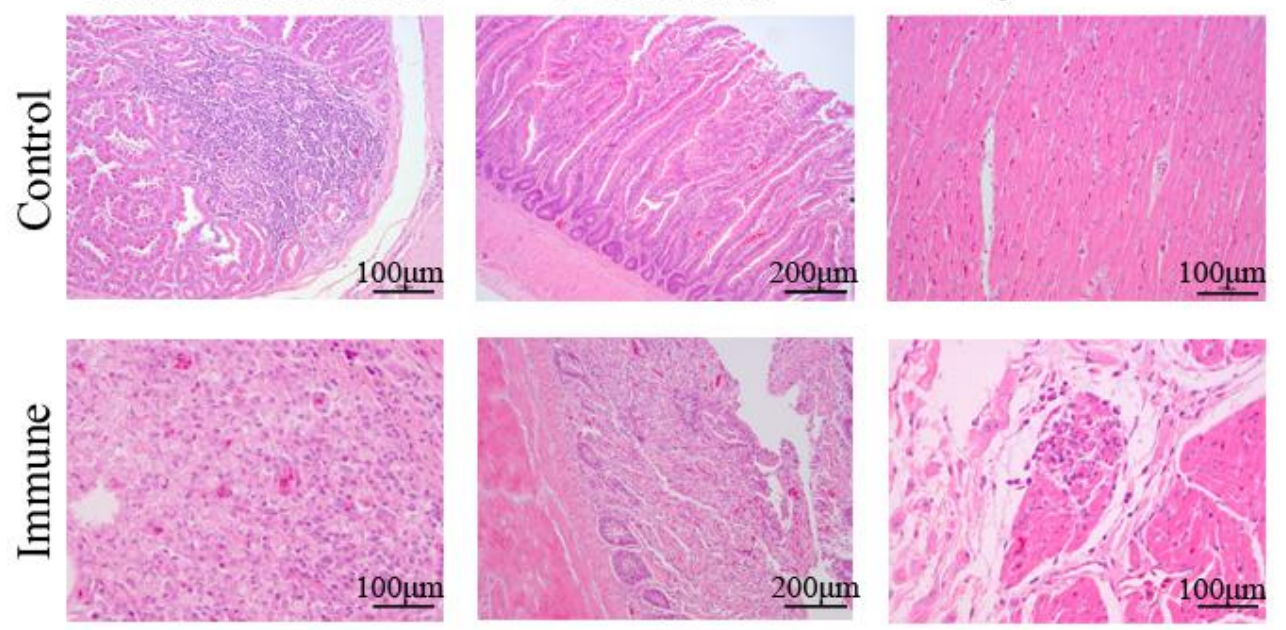

Fig. 8. Histopathological analyses of glandular stomach, duodenum, and myocardium obtained from

healthy chickens and those challenged with the highly virulent NDV strain F48E9. Tissues of the glandular

\section{Discussion}

259 Newcastle disease causes significant economic losses in the poultry industry every year. Traditional pathogen mutation risk and lower protection [22]. Therefore, methods to improve the immune efficacy of DNA vaccine have become the focus of vaccine researches. and delivery system [23]. Although plasmid DNA is quite stable in vitro, it is subject to degradation by nucleases once injected in vivo. Encapsulation of plasmid DNA in biodegradable polymer to form 
L-lactic-co-glycolic) acid (PLGA), gelatin and chitosan. Chitosan nanoparticles have been developed for the delivery of plasmid DNA due to their cationic charge, biodegradability, biocompatibility, low toxicity, mucoadhesivity and ability to enhance the penetration of large molecules across mucosal surface. When DNA vaccine is encapsulated into chitosan nanoparticles, the integrity of plasmid DNA on the mucosal surface can be protected and the mucoadhesivity is enhanced, thereby improving its immune induction to pathogens on the mucosa $[25,26]$. At present, chitosan nanoparticle adjuvant has been applied to a variety of DNA vaccines, including human and animal infectious diseases, for example reddish body iridovirus, nodavirus, foot and mouth disease virus and influenza virus [27, 28]. In order to overcome the defect that chitosan has poor water-solubility, chitosan derivative nanoparticles used in the study, O-2'-HACC nanoparticles, have better water solubility, biodegradability, biocompatibility, loading capacity and mucosal adsorption compared to chitosan. Due to the presence of negatively charged regions between the cells, thus, O-2'-HACC nanoparticles with positive charge can open cell junctions in these regions and change the shape of cytoskeleton protein, which allow the O-2'-HACC nanoparticles to pass mucosal epithelial cell barrier and be absorbed by M cells. Hence, O-2'-HACC nanoparticles can be served as vaccine adjuvant and delivery vector to improve immune effect, and the nanoparticles have many advantages than chitosan nanoparticles.

The particle size of nanoparticles is also an important quality indicator that affects transfection and the expression efficiency of target gene [29]. It is generally believed that the nanoparticles between $150-300 \mathrm{~nm}$ are most suitable for transfection. If the nanoparticles are too large, it is difficult to enter the target cells $[30,31]$. The particle size of O-2'-HACC/pFDNA prepared in our study is about $202.3 \mathrm{~nm}$, which may help the nano vaccine to enter host cells. Moreover, the level of antibodies induced by O-2'-HACC/pFDNA was significantly higher than that of commercial vaccines, which indicated that 
O-2'-HACC/pFDNA induced a relatively strong immune response.

Many DNA vaccines against human and animal infectious diseases have been developed [32-34].

294 These vaccines provided stable and sufficient supply of antigen in transfected host cells and induced

cellular immunity, mucosal immunity and long-lasting immunity [35-37], but most of DNA vaccines in use

or in clinic are injected intramuscularly or subcutaneously. Thus, mucosal immune response cannot be

induced. Mucosal vaccine has many advantages over injectable vaccine by being simpler to administer,

less risk of transmitting infections and potentially being easier to manufacture [38, 39]. In addition,

mucosal vaccination can induce humoral and cell-mediated antigen-specific immune responses, including

B cell and T cell memory responses [40].

Nasal-associated lymphoid tissue (NALT), which serves as a mucosal inductive site for immune

responses against antigen stimulation in the upper respiratory tract, has an important role in the induction

of mucosal immune response, including inducing the production of antigen-specific Th1 and Th2 cells and

sIgA antibody [41-45]. Moreover, intranasal immunization can lead to the induction of antigen-specific immunization is expected as a vaccine against pathogens causing upper respiratory tract infection such as fluid, bile and harderian gland was measured, the results demonstrated that the levels of sIgA antibody produced by the O-2'-HACC/pFDNA i.n. were higher than those of the O-2'-HACC/pFDNA i.m., and the 
the uptake rate of antigen-associated lymphoid tissue, thus, the levels of sIgA antibody were improved and induced better mucosal immunity in the O-2'-HACC/pFDNA i.n.

T helper cells are key cells regulating humoral and cellular immunity. The functionally active region of T helper cells is divided into two cell subpopulations, Th1 and Th2 cells. Cellular immunity involves CD4+ and CD8+ T lymphocytes. CD4+ T lymphocytes can differentiate into Th1 cells or Th2 cells. Th1 cells support cellular-mediated immune responses, while Th2 cells drive humoral immune responses [48]. IL-2 mainly enhances cellular immunity, IL-4 mainly regulates humoral immunity, and IFN- $\gamma$ mainly regulates immune response by participating in Th-type cells to differentiate into Th1 type [49]. Therefore, IL-2 and IFN- $\gamma$ enhance the Th1 type immune response, and IL-4 can enhance the Th2 type immune response [50]. The levels of IL-2, IL-4 and IFN- $\gamma$ in serum of chickens immunized with the O-2'-HACC/pFDNA i.n. were significantly higher, and the cytokine levels induced by the mucosal immune pathway were higher than those of the non-mucosal immune pathway, which the O-2'-HACC/pFDNA i.n. promoted the lymphocyte proliferation and cellular response and better induce Th1 and Th2 type responses, indicating that the O-2'-HACC/pFDNA via the mucosal route stimulated the body to produce strong cellular, humoral and local mucosal immunity.

After functional modification, chitosan derivatives can improve the various properties of chitosan, such as water solubility, stability, membrane permeability, mucosal adhesion and controlled release, etc. The study provided a theoretical basis for the application of quaternized chitosan nanoparticles as adjuvant and delivery system for DNA vaccines in some viral infectious disease vaccines, and have the great potential in the field of mucosal vaccines. Despite these advantages, chitosan derivatives nanoparticles as adjuvant and delivery vector for DNA vaccine are still in its early stages, and more clinical trials are needed for verification, such as irregular distribution and low physical stability etc., which hinder the 
commercialization of chitosan. Therefore, it is highly desirable to study safe, efficient and targeted vaccine delivery system to prevent and control certain infectious diseases [26]. All problems will be solved in the near future with the development and application of nanotechnology, because one of the most attractive

fields in nanotechnology is the use of nanomaterials as vaccine adjuvant and delivery system, and so many nanomaterials have been studied for the delivery of drugs, imaging, diagnostic and vaccines. In conclusion, the use of chitosan derivatives nanoparticles is having a significant impact on vaccinology with the perspective to obtain novel biological products to fight high pathogenic infectious diseases.

\section{Materials and method}

\section{Animals}

Two hundred and ten 1-day-old healthy SPF chickens are provided and raised by the Experimental Animal Center of Harbin Veterinary Research Institute, Chinese Academy of Agricultural Sciences. All of the animal experimental procedures were approved by the Animal Ethics Committee as stipulated in the guide to the care and use of experimental animals of Harbin Veterinary Research Institute. SPF chickens were housed in the center's negative pressure isolator during the test. The chickens were euthanized by intravenous injection of pentobarbital.

\section{Preparation of the O-2'-HACC/PFDNA}

We prepared the O-2'-HACC nanoparticles loaded with NDV F gene plasmid DNA (O-2'-HACC/pFDNA) using the polyelectrolyte complex method. The water soluble quaternized chitosan nanoparticles, O-2'-HACC nanoparticles, were synthesized as vaccine adjuvant and delivery vector according to described previously [21]. NDV F gene eukaryotic expression plasmid pVAX-optiF with C3d6 molecular adjuvant (pVAX I -F(o)-C3d6) was constructed by our group [51].

\section{Characterization of the O-2'-HACC/pFDNA}




\section{DNase I protection assay} $\min$.

\section{In vitro release of the O-2'-HACC/pFDNA}


To investigate the storage stability of the freeze-dried O-2'-HACC/pFDNA stored at room temperature

chickens were randomly selected and equally divided into three groups, chickens in Group 1 were nano vaccine stored at room temperature for two months, chickens in Group 3 were administrated with the to measure the anti-NDV IgG antibody by hemagglutination inhibition (HI).

\section{In vitro expression of the $O-2$ '-HACC/pFDNA}

transfection was carried out by the Lipofectamine ${ }^{\mathrm{TM}} 2000$ reagent kit (Invitrogen, USA). Group 1 was the microscopy (Zeiss, Germany). 


\section{Nasal immunization}

One hundred and twenty 18-day-old healthy SPF chickens were randomly divided into six groups

with twenty chickens in each group, and chickens in each group were separately housed in a stainless-steel isolator in a temperature- and light-controlled environment with free access to food and water ad libitum. Each chicken was given an immunization dose of $100 \mu$ l containing $200 \mu \mathrm{g}$ of the plasmid DNA. Chickens in Group 1 were administered $100 \mu \mathrm{l}$ PBS buffer intramuscular (i.m.), chickens in Groups 2 were administered $100 \mu \mathrm{l}$ of O-2'-HACC NPs i.m., chickens in Groups 3 were administered $100 \mu 1$ of the plasmid DNA i.m., chickens in Groups 4 were administered $100 \mu$ of O-2'-HACC/pFDNA containing 200 $\mu \mathrm{g}$ of the plasmid DNA i.m., chickens in Group 5 were administered $100 \mu \mathrm{l}$ of O-2'-HACC/pFDNA containing $200 \mu \mathrm{g}$ of the plasmid DNA intranasal (i.n.), chickens in Groups 6 were administered $100 \mu 1$ of attenuated live NDV vaccine i.m. The attenuated live NDV vaccine (L/N: 200805) provided by Harbin Pharmaceutical Group Bio-vaccine Co. Ltd.

Blood samples were collected via heart from two chickens in each of the six groups at 1, 2, 3, 4, 5, 6, 7, 8, 9 and 10 weeks post the immunization, respectively. Serum was obtained by centrifugation at $4^{\circ} \mathrm{C}$, $3000 \mathrm{r} / \mathrm{min}$ for $10 \mathrm{~min}$ to measure the anti-NDV IgG antibody titers, and the levels of IFN- $\gamma$, IL-2 and IL-4 by ELISA kit (Thermo Fisher Scientific Inc, MA, USA) and CD4+ and CD8+ T lymphocytes distribution by FACSAria flow cytometer (BD Biosciences, San Diego, CA, USA). At the same time, to assess the mucosal immune response, sIgA antibody titers in serum, tracheal fluid, bile and harderian glands were measured using the NDV IgA ELISA Kit (Rapidbio Co. Ltd, Beijing, China). Additionally, to detect the cellular-mediated immune response, splenocytes were harvested to determine the lymphocyte proliferation by MTT colorimetric assay as previously described [21].

\section{Protective efficacy against NDV strain F48E9}



immunization, seven chickens were selected randomly from each of the six groups and challenged with $100 \mu \mathrm{l}$ of viral suspension containing $10^{4.5} \mathrm{EID}_{50} / 0.1 \mathrm{ml}$ of F48E9 via nasal drop. Any abnormal changes such as feed, water drinking, mental state, body weight, clinical symptoms and mortality were observed and recorded for 35 days. On day 7th, 14th, 21th, 28th, and 35th after challenge, blood samples were collected for the analysis of serum HI antibody and the contents of IFN- $\gamma$, IL-2, and IL-4. Simultaneously, the infected chickens and chickens in negative control groups were euthanized, and their glandular stomach, duodenum and myocardium were collected to examine the histopathological changes by histological staining. Chickens were sacrificed by an overdose of a mixture of isoflurane $/ \mathrm{O}_{2}$.

\section{Statistical analysis} variance (ANOVA) was employed to evaluate the statistical differences among different groups with SPSS 19.0 software. The difference between groups with $P<0.05$ was considered to be statistically significant.

\section{Declarations}

\section{Ethics approval and consent to participate}

440 All of the animal experimental procedures were approved by the Animal Ethics Committee as stipulated in

441 the guide to the care and use of experimental animals of Harbin Veterinary Research Institute.

\section{Consent for publication}

443 All authors agreed to submit this manuscript.

\section{Competing interests}

445 The authors declare that they have no competing interests. 


\section{Acknowledgments}

This work was supported in part by the National Natural Science Foundation of China (31771000),

Zhejiang Provincial Key R\&D Program of China (2021C02049) and Young Eagle Plan for Cultivation

Special Project of Scientific and Technological Enterprise in Harbin (2020CYJBCG0306).

\section{References}

[1] Martella E, Ferroni C, Guerrini A, Ballestri M, Columbaro M, Santi S, Sotgiu G, Serra M, Donati DM, Lucarelli E, Varchi G, Duchi S. Functionalized keratin as nanotechnology-based drug delivery system for the pharmacological treatment of osteosarcoma. Int J Mol Sci. 2018;19(11):3670.

[2] Li H, Piao D, Jiang T, Bok J, Cho C, Lee Y, Kang S, Choi Y. Recombinant interleukin 6 with M cell-targeting moiety produced in Lactococcus lactis IL1403 as a potent mucosal adjuvant for peroral immunization. Vaccine. 2015;33:1959-67.

[3] Rhee JH, Lee SE, Kim SY, Mucosal vaccine adjuvants update. Clin Exp Vaccine Res. 2012;1(1):50-63.

[4] Tang Q, Wang J, Bao J, Sun H, Sun Y, Liu J, Pu J. A multiplex RT-PCR assay for detection and differentiation of avian $\mathrm{H} 3, \mathrm{H} 5$, and $\mathrm{H} 9$ subtype influenza viruses and Newcastle disease viruses. J Virol Methods. 2012;181(2):164-9.

[5] Balasubramaniam VR, Wai TH, Omar AR, Othman I, Hassan SS. Cellular transcripts of chicken brain tissues in response to H5N1 and Newcastle disease virus infection. Virol J. 2012;9:53.

[6] Welch CN, Shittu I, Abolnik C, Solomon P, Dimitrov KM, Taylor TL, Williams-Coplin D, Goraichuk IV, Meseko CA, Ibu JO, Gado DA, Joannis TM, Afonso CL. Genomic comparison of Newcastle disease viruses isolated in Nigeria between 2002 and 2015 reveals circulation of highly diverse genotypes and spillover into wild birds. Arch Virol. 2019;164(8):2031-47.

[7] Lee L, Izzard L, Hurt AC. A review of DNA vaccines against influenza. Front Immunol. 2018;9:1568.

[8] Abdulrahman A, Ghanem A. Recent advances in chromatographic purification of plasmid DNA for gene therapy and DNA vaccines: A review. Anal Chim Acta. 2018;1025:41-57.

[9] Xiang SD, Selomulya C, Ho J, Apostolopoulos V, Plebanski M. Delivery of DNA vaccines: an overview on the use of biodegradable polymeric and magnetic nanoparticles. Nanomed 
Nanobiotechnol. 2010;2(3):205218.

475

476

477

[10] Tiptiri-Kourpeti A, Spyridopoulou K, Pappa A, Chlichlia K. DNA vaccines to attack cancer: Strategies for improving immunogenicity and efficacy. Pharmacol Ther. 2016;165:32-49.

[11] Wang T, Upponi JR, Torchilin VP. Design of multifunctional non-viral gene vectors to overcome physiological barriers: dilemmas and strategies. Int J Pharm. 2012;427(1):3-20.

[12] Humphreys IR, Sebastian S. Novel viral vectors in infectious diseases. Immunology. 2018;153(1)):1-9.

[13] Rai R, Alwani S, Badea I. Polymeric nanoparticles in gene therapy: New avenues of design and optimization for delivery applications. Polymers. 2019;11(4):745.

[14] Patil S, Gao YG, Lin X, Li Y, Dang K, Tian Y, Zhang WJ, Jiang SF, Qadir A, Qian AR. The development of functional non-viral vectors for gene delivery. Int J Mol Sci. 2019;20(21):5491.

[15] Park TG, Jeong JH, Kim SW. Current status of polymeric gene delivery systems. Adv Drug Deliv Rev. $2006 ; 58(4): 467-86$.

[16] Zhao K, Shi X, Zhao Y, Wei H, Sun Q, Huang T, Zhang X, Wang Y. Preparation and immunological effectiveness of a swine influenza DNA vaccine encapsulated in chitosan nanoparticles. Vaccine. 2011;29(47):8549-56.

[17] Zhao K, Li GX, Jin YY, Wei HX, Sun QS, Huang TT, Wang YF, Tong GZ. Preparation and immunological effectiveness of a Swine influenza DNA vaccine encapsulated in PLGA microspheres. J Microencapsul. 2010;27(2):178-86.

[18] Chua BY, Al KM, Zeng W, Mainwaring D, Jackson DC. Chitosan microparticles and nanoparticles as biocompatible delivery vehicles for peptide and protein-based immunocontraceptive vaccines. Mol Pharm. 2012;9(1):81-90.

[19] Amaduzzi F, Bomboi F, Bonincontro A, Bordi F, Casciardi S, Chronopoulou L, Diociaiuti M, Mura F, Palocci C, Sennato S. Chitosan-DNA complexes: charge inversion and DNA condensation. Colloids Surf B Biointerfaces. 2014;114:1-10.

[20] Botelho DSS, Krolicka M, van den Broek L, Frissen AE, Boeriu CG. Water-soluble chitosan derivatives and $\mathrm{pH}-$-responsive hydrogels by selective C-6 oxidation mediated by TEMPO-laccase redox system. Carbohydr Polym. 2018;186:299-309.

[21] Dai CX, Kang H, Yang WQ, Sun JY, Liu CL, Cheng GG, Rong GY, Wang XH, Wang X, Jin Z, Zhao K. O-2'-Hydroxypropyl trimethyl ammonium chloride chitosan nanoparticles for the delivery of live 
[22] Gong Q, Kong LY, Niu MF, Qin CL, Yang Y, Li X, Ruan MD, Tian Y, Li ZL. Construction of a ptfA chitosan nanoparticle DNA vaccine against Pasteurella multocida and the immune response in chickens. Vet J. 2018;231:1-7.

[23] Li L, Petrovsky N. Molecular adjuvants for DNA vaccines. Curr Issues Mol Biol. 2017;22:17-40.

[24] Bozkir A, Saka OM. Chitosan nanoparticles for plasmid DNA delivery: Effect of chitosan molecular structure on formulation and release characteristics. Drug Deliv. 2004;11:107-12.

[25] Wu M, Zhao H, Li M, Yue Y, Xiong S, Xu W. Intranasal vaccination with mannosylated chitosan

[28] Tahamtan A, Barati M, Tabarraei A, Mohebbi SR, Shirian S, Gorji A, Ghaemi A. Antitumor immunity induced by genetic immunization with chitosan nanoparticle formulated adjuvanted for HPV-16 E7 DNA vaccine. Iran J Immunol. 2018;15(4):269-80.

[29] Yang XR, Zong L, Yuan XY. Chitosan nanoparticles as gene vector: effect of particle size on transfection efficiency. Acta Pharmaceutica Sinica. 2007;42(7):774-9.

[30] Kole S, Kumari R, Anand D, Kumar S, Sharma R, Tripathi G, Makesh M, Rajendran KV, Bedekar MK. Nanoconjugation of bicistronic DNA vaccine against Edwardsiella tarda using chitosan nanoparticles: Evaluation of its protective efficacy and immune modulatory effects in Labeo rohita vaccinated by different delivery routes. Vaccine. 2018;36(16):2155-65.

[31] Sahdev P, Ochyl LJ, Moon JJ. Biomaterials for nanoparticle vaccine delivery systems. Pharm Res. 2014;31(10):2563-82.

[32] McBurney SP, Sunshine JE, Gabriel S, Huynh JP, Sutton WF, Fuller DH, Haigwood NL, Messer WB. Evaluation of protection induced by a dengue virus serotype 2 envelope domain III protein 
scaffold/DNA vaccine in non-human primates. Vaccine. 2016;4(30):3500-7.

[33] Xu Q, Cui N, Ma X, Wang F, Li H, Shen Z, Zhao X. Evaluation of a chimeric multi-epitope-based DNA vaccine against subgroup J avian leukosis virus in chickens. Vaccine. 2016;34(33):3751-6.

[34] Golshani M, Rafati S, Siadat SD, Nejati-Moheimani M, Shahcheraghi F, Arsang A, Bouzari S. Improved immunogenicity and protective efficacy of a divalent DNA vaccine encoding Brucella L7/L12-truncated Omp31 fusion protein by a DNA priming and protein boosting regimen. Mol Immunol. 2015;66(2):384-91.

[35] Smith T, Schultheis K, Morrow MP, Kraynyak KA, McCoy JR, Yim KC, Muthumani K, Humeau L, Weiner DB, Sardesai NY, Broderick KE. Development of an intradermal DNA vaccine delivery strategy to achieve single-dose immunity against respiratory syncytial virus. Vaccine. 2017;35(21): $2840-7$.

[36] Sun B, Yu S, Zhao D, Guo S, Wang X, Zhao K. Polysaccharides as vaccine adjuvants. Vaccine. 2018;36(35):5226-34.

[37] Gurunathan S, Wu CY, Freidag BL, Seder RA. DNA vaccines: a key for inducing long-term cellular immunity. Curr. Opin Immunol. 2000;12(4):442-7.

[38] Baleeiro RB, Schweinlin M, Rietscher R, Diedrich A, Czaplewska JA, Metzger M, Lehr CM, Scherlieb R, Hanefeld A, Gottschaldt M, Walden P. Nanoparticle-based mucosal vaccines targeting tumor-associated antigens to human dendritic cells. J Biomed Nanotechnol. 2016;12(7):1527-43.

[39] Zanin M, Baviskar P, Webster R, Webby R. The interaction between respiratory pathogens and mucus. Cell Host Microbe. 2016;19(2):159-68.

[40] Lycke N. Recent progress in mucosal vaccine development: potential and limitations. Nat Rev Immunol. 2012;12(8):592-605.

[41] Lee H, Ruane D, Law K, Ho Y, Garg A, Rahman A, Esterhazy D, Cheong C, Goljo E, Sikora AG, Mucida D, Chen BK, Govindraj S, Breton G, Mehandru S. Phenotype and function of nasal dendritic cells. Mucosal Immunol. 2015;8(5):1083-98.

[42] Mutoh M, Kimura S, Takahashi-Iwanaga H, Hisamoto M, Iwanaga T, Iida J. RANKL regulates differentiation of microfold cells in mouse nasopharynx-associated lymphoid tissue (NALT). Cell Tissue Res. 2016;364(1):175-84.

[43] Yu YY, Kong W, Yin YX, Dong F, Huang ZY, Yin GM, Dong S, Salinas I, Zhang YA, Xu Z. Mucosal immunoglobulins protect the olfactory organ of teleost fish against parasitic infection. Plos Pathog. 
2018;14(11):e1007251.

[44] Kraehenbuhl JP, Neutra MR. Mucosal vaccines: where do we stand? Curr Top Med Chem. 2013;13(20):2609-28.

[45] Ogra PL. Mucosal immunity: some historical perspective on host-pathogen interactions and implications for mucosal vaccines. Immunol Cell Biol. 2003;81(1):23-33.

[46] Kiyono H, Fukuyama S. NALT- versus Peyer's-patch-mediated mucosal immunity. Nat Rev Immunol. 2004;4(9):699-710.

[47] Takaki H, Ichimiya S, Matsumoto M, Seya T. Mucosal immune response in nasal-associated lymphoid tissue upon intranasal administration by adjuvants. J Innate Immun. 2018;10:515-21.

573 [48] Yan XY, Zhou M, Yu S, Jin Z, Zhao K. An overview of biodegradable nanomaterials and applications in vaccines. Vaccine. 2020;38(5):1096-104.

[49] Nair S, Bayer W, Ploquin MJ, Kassiotis G, Hasenkrug KJ, Dittmer U. Distinct roles of CD4+ T cell subpopulations in retroviral immunity: lessons from the Friend virus mouse model. Retrovirology. $2011 ; 8: 76$.

[50] Rauw F, Gardin Y, Palya V, Anbari S, Lemaire S, Boschmans M, van den Berg T, Lambrecht B. Improved vaccination against Newcastle disease by an in ovo recombinant HVT-ND combined with an adjuvanted live vaccine at day-old. Vaccine. 2010;28(3):823-33.

[51] Zhao K, Duan XT, Hao LW, Wang XH, Wang YF. Immune effect of Newcastle disease virus DNA vaccine with C3d as a molecular adjuvant. J Microbiol Biotechnol. 2017;27(11):2060-9. 


\section{Figures}
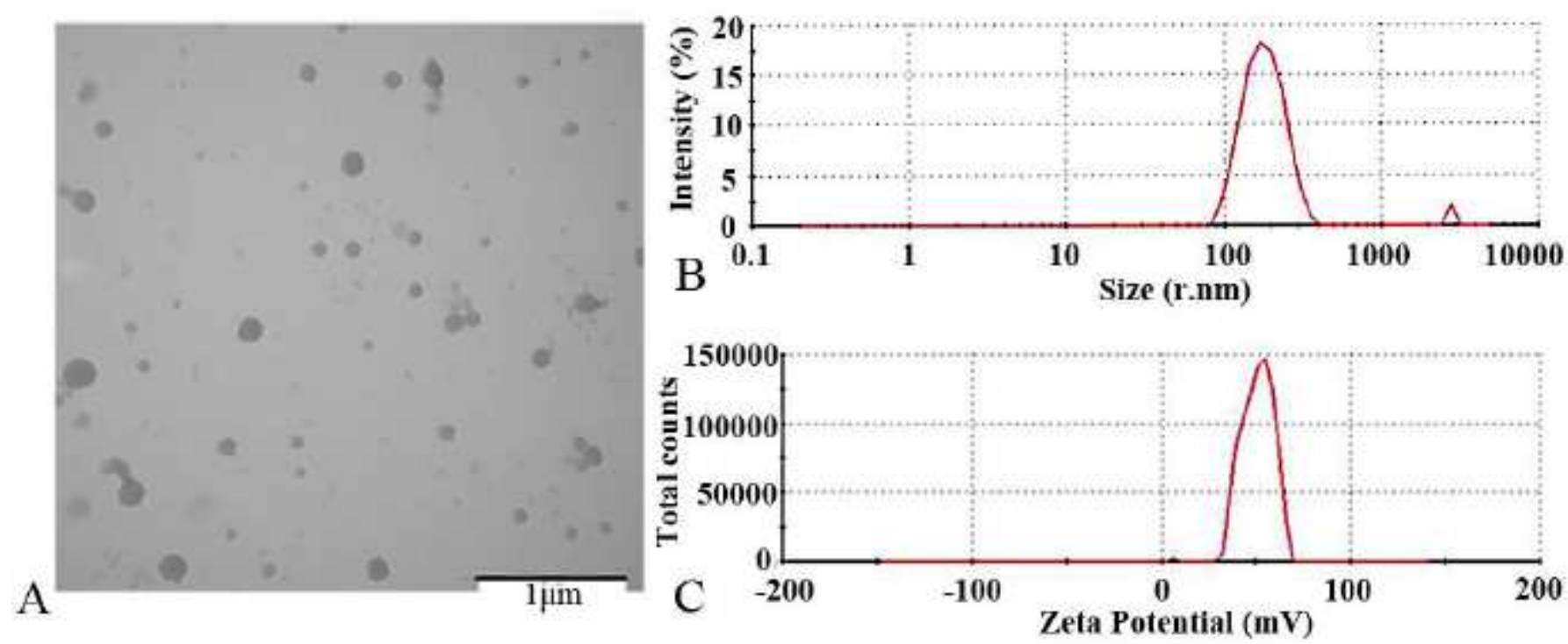

Figure 1

Characterization of the 0-2'-HACC/pFDNA. (A) Transmission electron microscope of 0-2'-HACC/pFDNA; (B) Particle size of 0-2'-HACC/pFDNA; (C) Zeta potential of 0-2'-HACC/pFDNA.

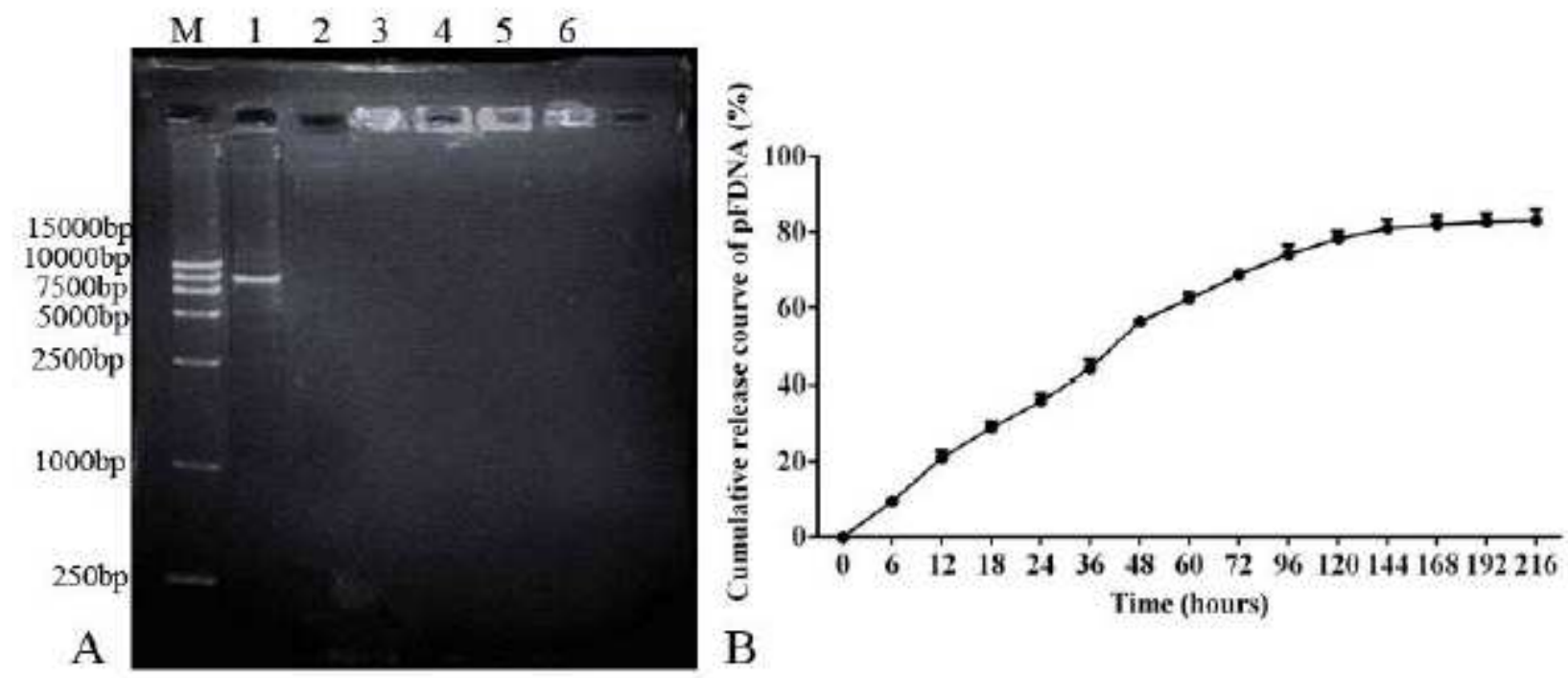

\section{Figure 2}

Stability and in vitro release analysis of the plasmid pVAX $\nabla-F(0)-C 3 d 6$ after encapsulation in the 0-2'HACC nanoparticles. (A) DNase $₫$ protection of the pVAX $\otimes-F(0)-C 3 d 6, M:$ DL 15000 Marker, Lane 1: pVAX

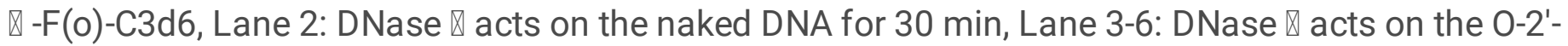
HACC/pFDNA for 30, 60, 120 and $180 \mathrm{~min}$; (B) In vitro release profiles of the 0-2'-HACC/pFDNA in PBS solution $(\mathrm{pH}=7.4)$. Data are presented as the mean \pm SD deviation $(n=3)$. 

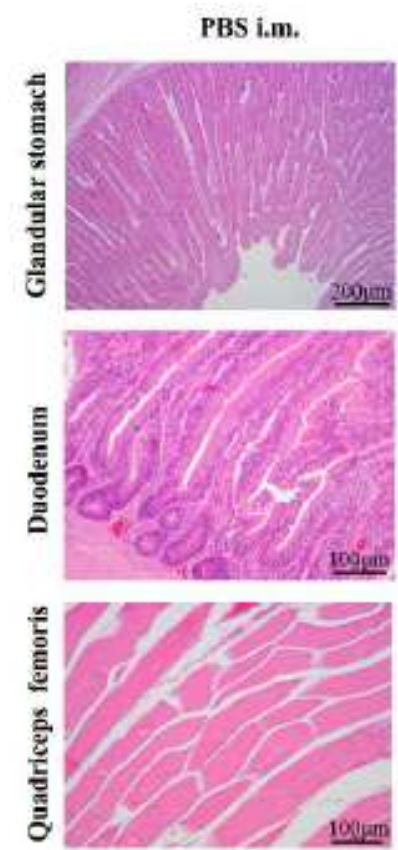

A

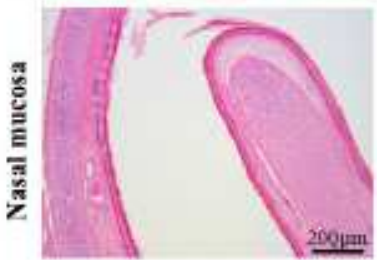

O-2'-HACC/pFDNA i.n.
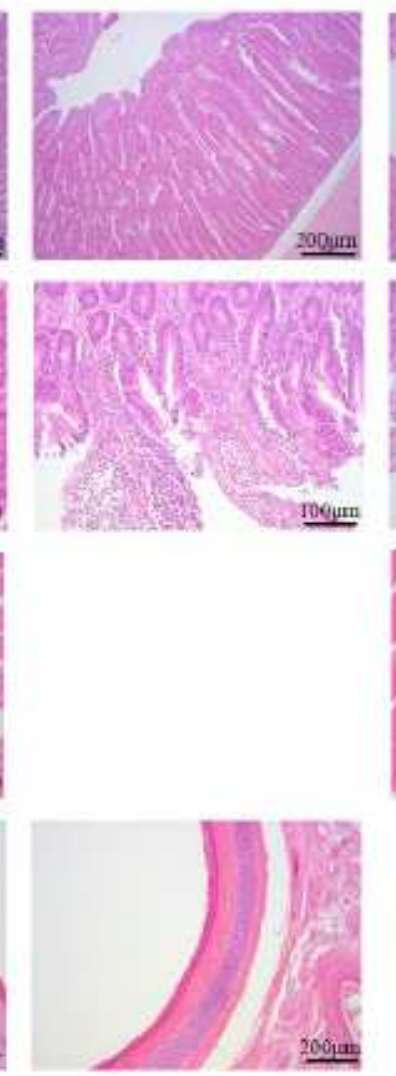
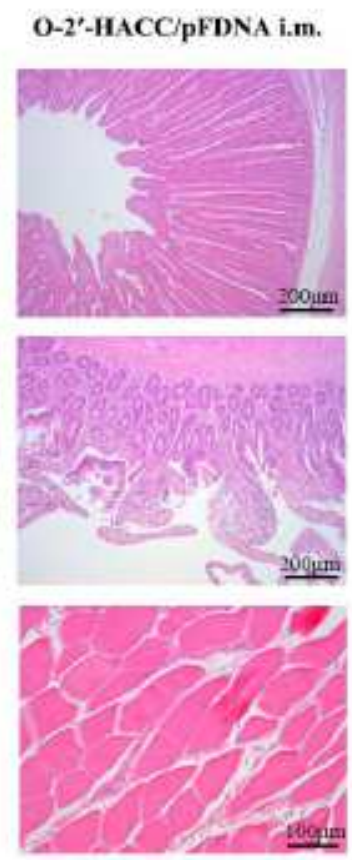

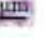
$\mathrm{B}$
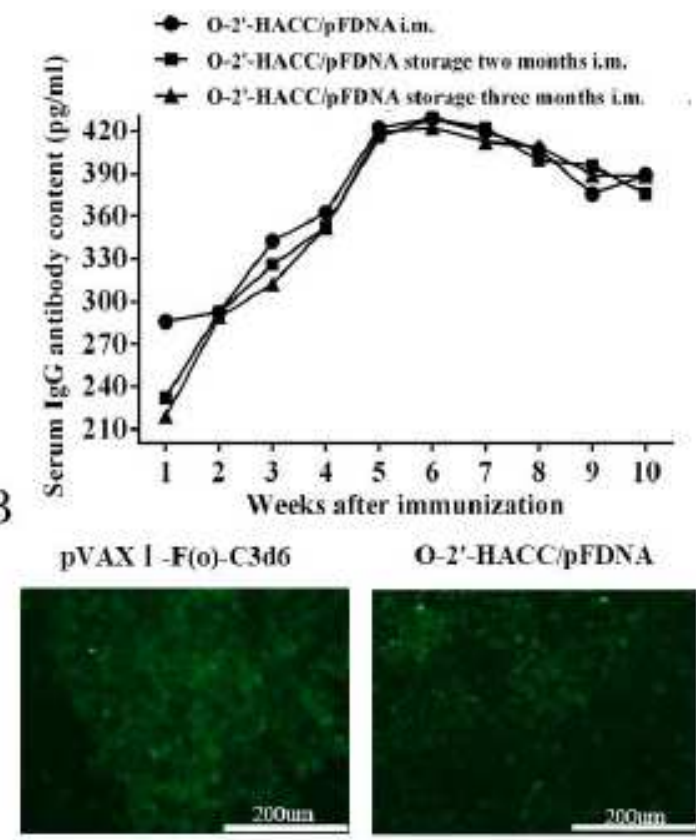

Blank O-2'-HACC NPs

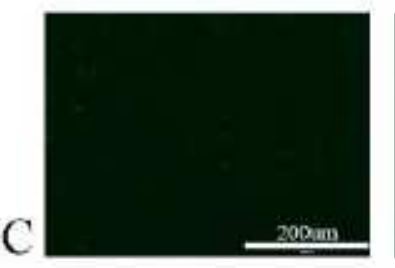

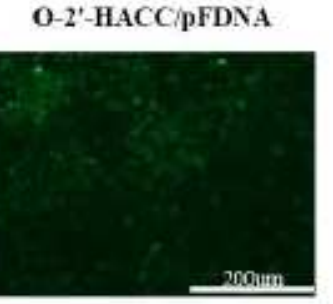

Control

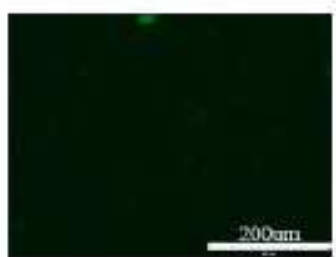

\section{Figure 3}

Safety analysis, in vitro fluorescence expression and storage stability of the 0-2'-HACC/pFDNA. (A) Histopathological analyses of glandular stomach, duodenum, quadriceps femoris and nasal mucosa; (B) In vitro expression of the 0-2'-HACC/pFDNA in 293T cells assayed by indirect immunofluorescence $(\times 40)$; (C) After Storage stability of the 0-2'-HACC/pFDNA for two and three months at room temperature, IgG titers in serum post the immunization. 
$\rightarrow$ PBS i.m.

$\rightarrow$ O-2'-HACC NPs i.m.

- pVAX I-F(o)-C3d6 i.m.

A Attenuated live ND vaccine i.m.

$\diamond$ 0-2'-HACC/pFDNA i.m.

* 0-2'-HACC/pFDNAi.n.

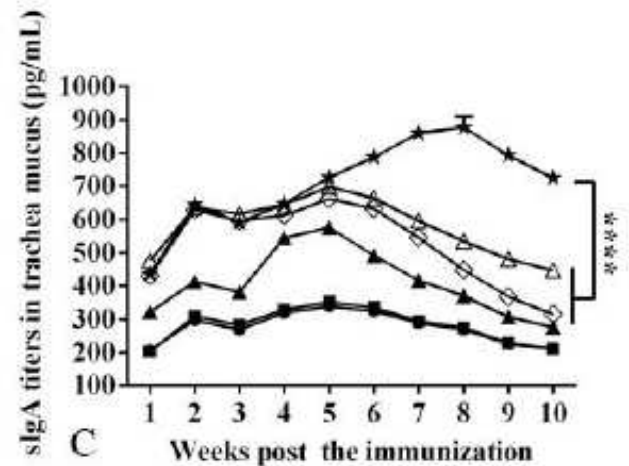

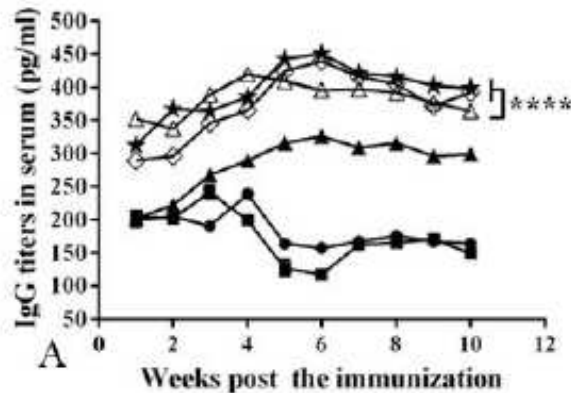

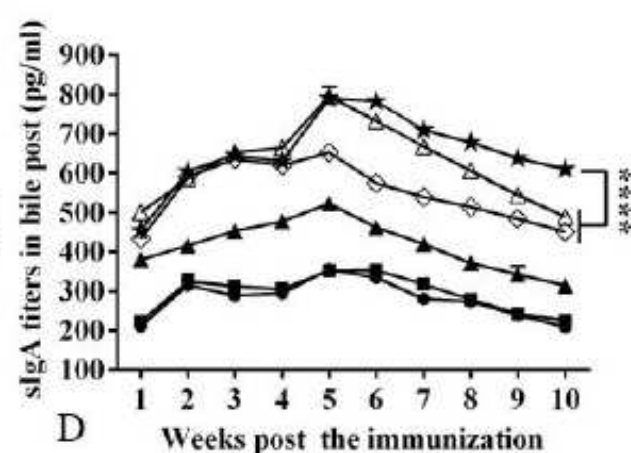

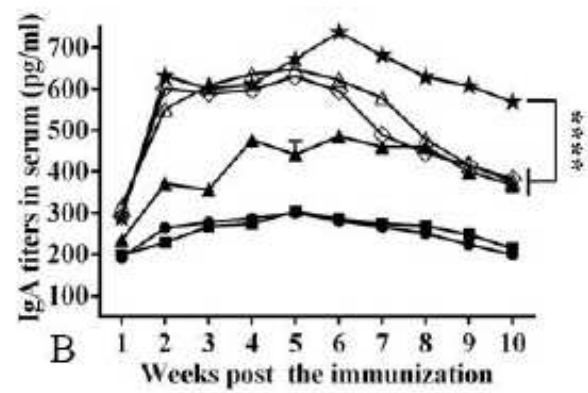

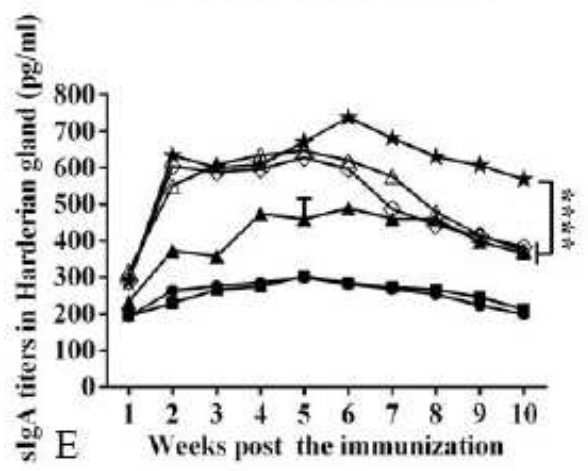

Figure 4

IgG and IgA antibody titers in serum (A, B), trachea mucus (C), bile (D), and harderian gland (E) following administration of PBS i.m., 0-2'-HACC NPs i.m., pVAX I-F(o)-C3d6 i.m., attenuated live ND vaccine i.n., 02'-HACC/pFDNA i.m., 0-2'-HACC/pFDNA i.n. Data are representative of three independent experiments and presented as the mean \pm SD $(n=3) .{ }^{*} P<0.05 ; * * P<0.01$.
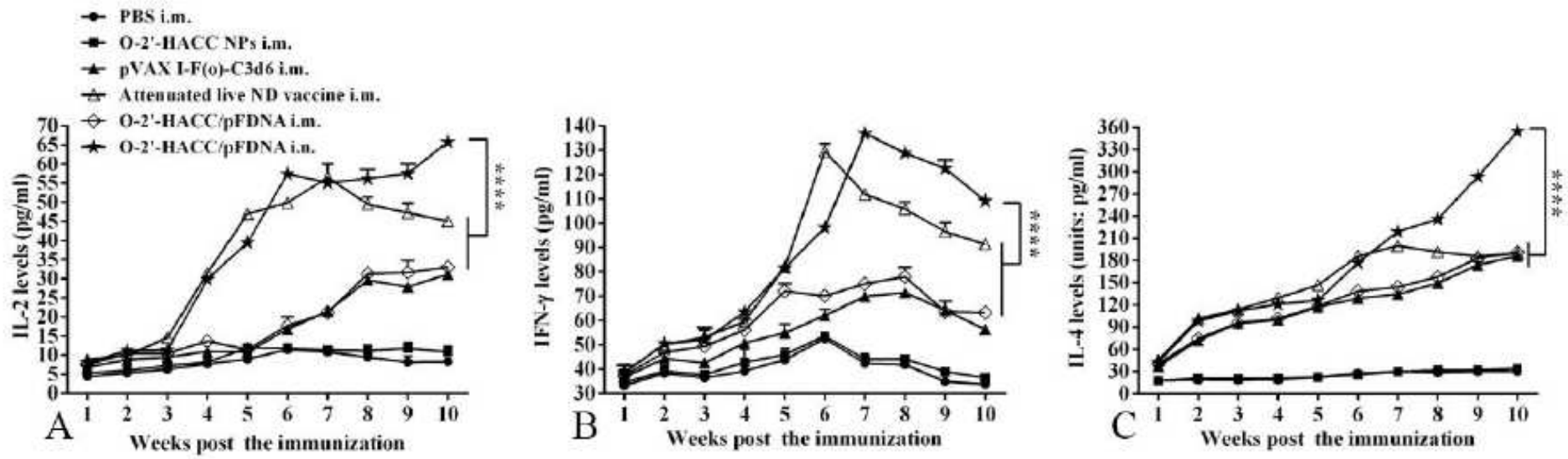

Figure 5

IL-2 (A), IL-4 (B), and IFN-ץ (C) levels in the supernatant of splenocytes harvested from the SPF chickens immunized with the PBS i.m., 0-2'-HACC NPs i.m., pVAX I-F(o)-C3d6 i.m., attenuated live ND vaccine i.n., 0-2'-HACC/pFDNA i.m., 0-2'-HACC/pFDNA i.n. IFN-y, IL-2, and IL-4 levels in the supernatant were analyzed in a chicken IFN- $\gamma$, IL-2, and IL-4 enzyme-linked immunosorbent assay. 
$15 d$ post the immunization
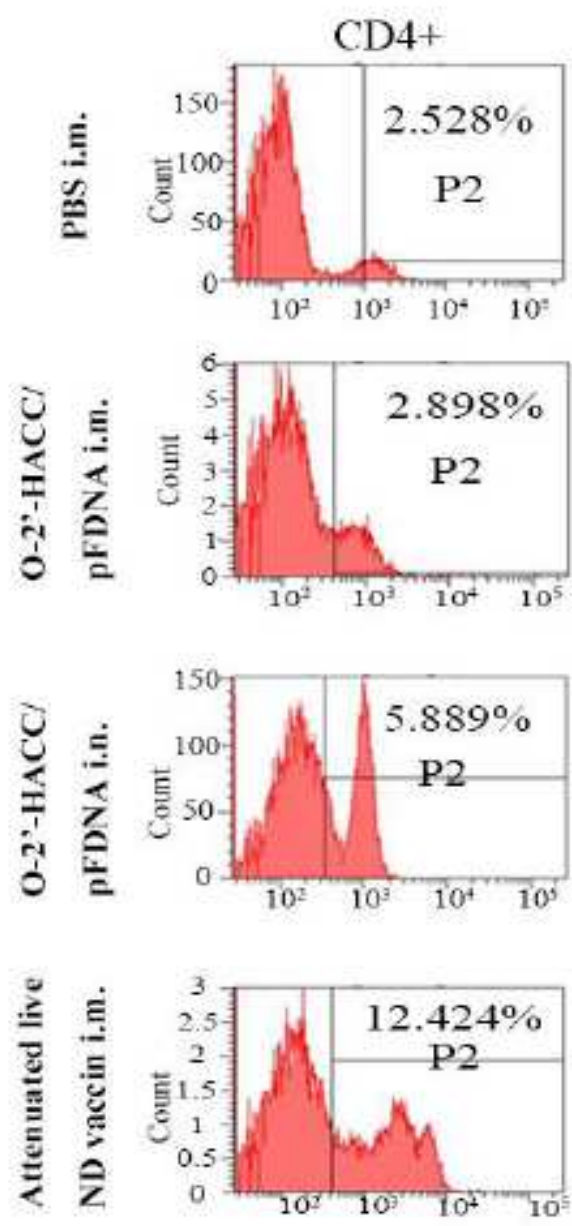

$30 \mathrm{~d}$ post the immunization
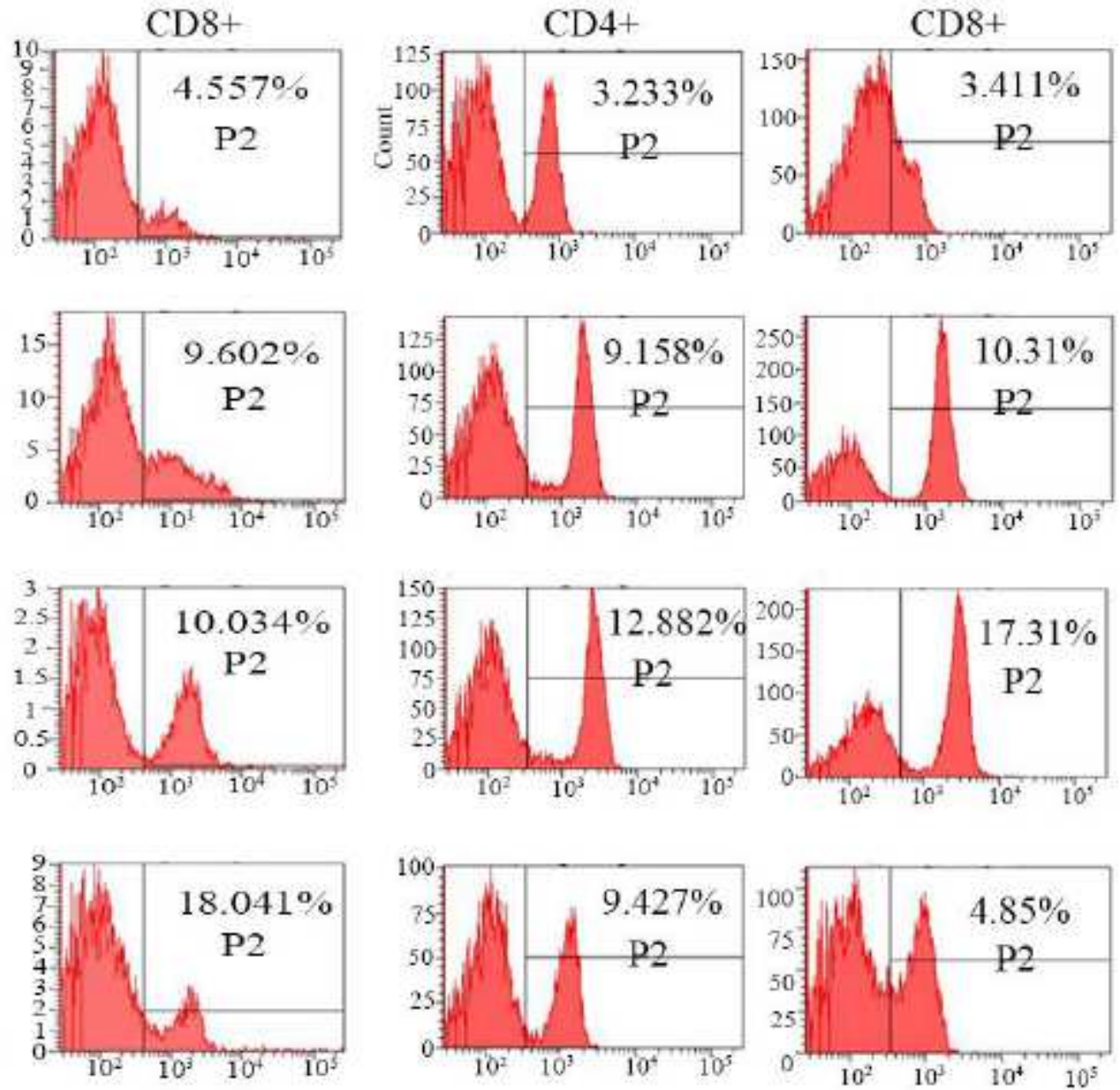

Figure 6

Levels of CD4+ and CD8+ T lymphocytes in peripheral blood post 15 days and 30 days after the immunization. 

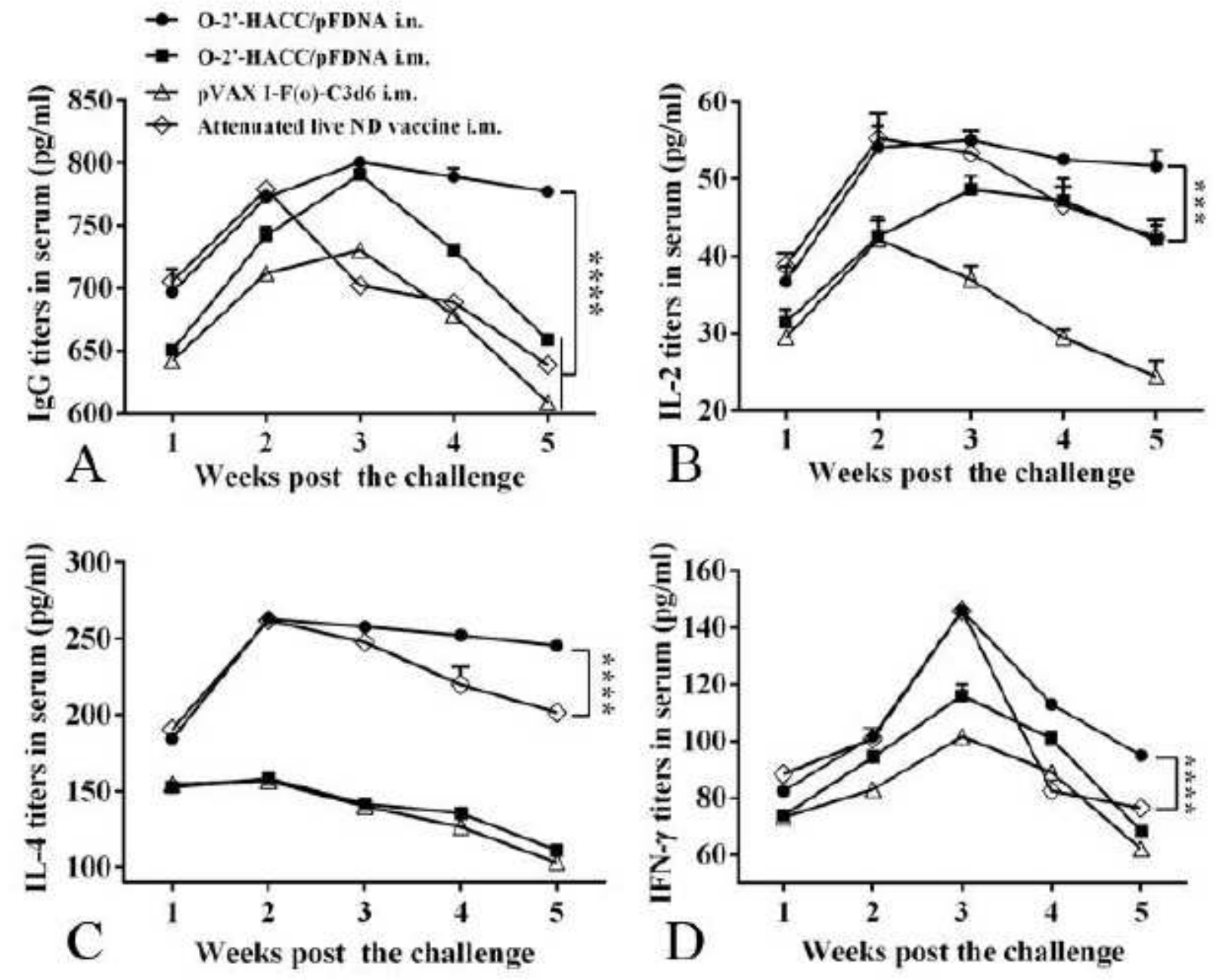

Figure 7

Serum IgG antibody titers (A) and IL-2 (B), IL-4 (C), IFN-Y (D) levels in the supernatant of splenocytes harvested from the immunized SPF chickens after challenge with the highly virulent NDV strain F48E9. IFN- $\gamma$, IL-2, and IL-4 levels in the supernatant were analyzed in a chicken IFN- - , IL-2, and IL-4 enzymelinked immunosorbent assay. Results are represented as mean \pm SD of three separate experiments. $* \mathrm{P}<0.05$. 
Glandular stomach
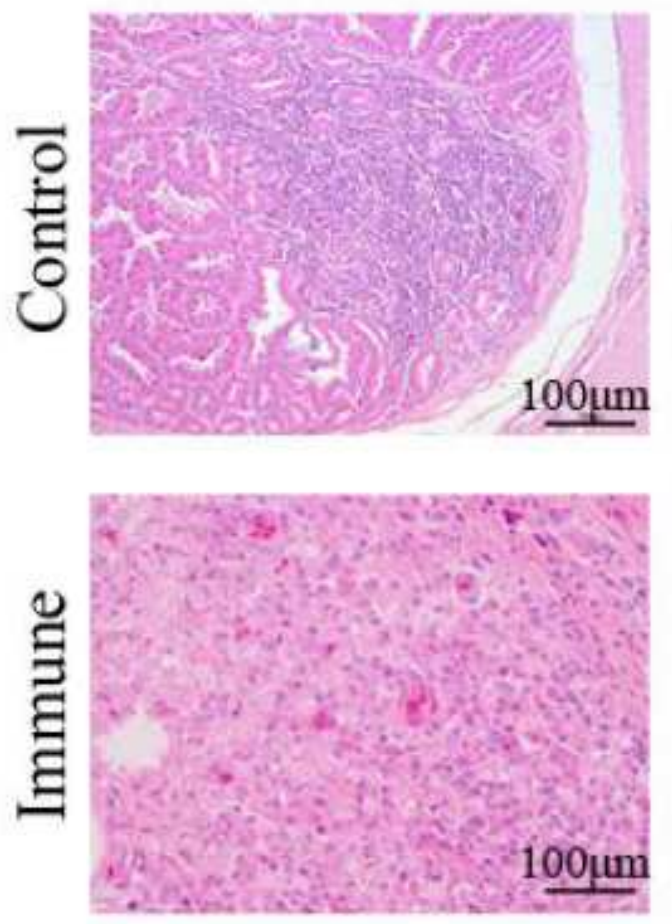

Duodenum
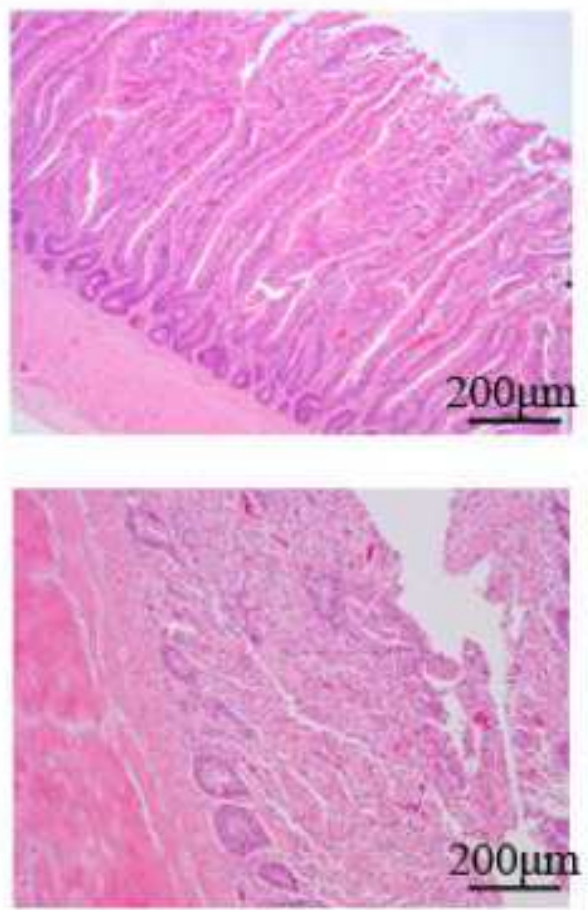

Myocardium
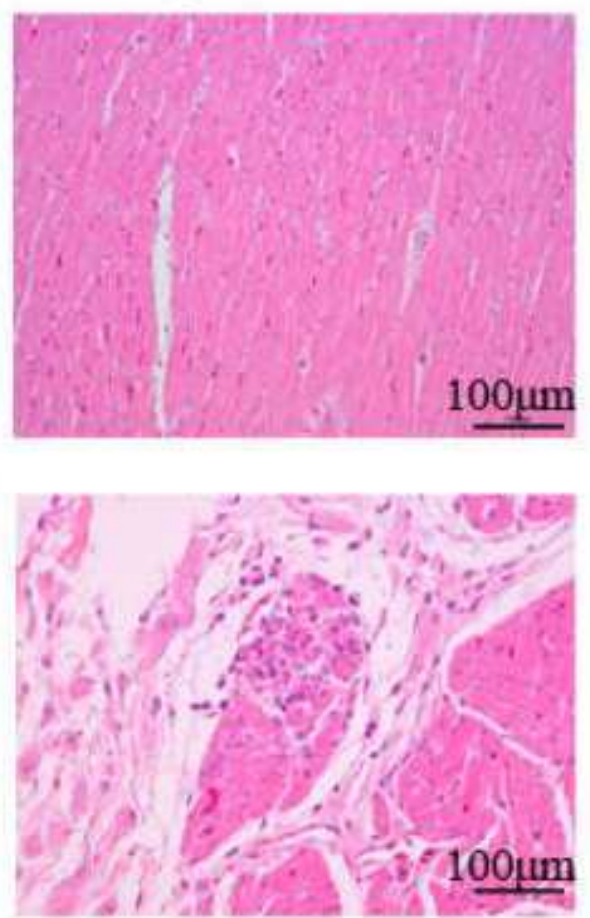

Figure 8

Histopathological analyses of glandular stomach, duodenum, and myocardium obtained from healthy chickens and those challenged with the highly virulent NDV strain F48E9. Tissues of the glandular stomach, duodenum, and myocardium from the PBS i.m., blank 0-2'-HACC nanoparticles i.n., attenuated live ND vaccine i.m., and O-2'-HACC/pFDNA i.m. and i.n. groups.

\section{Supplementary Files}

This is a list of supplementary files associated with this preprint. Click to download.

- GraphicalAbstract.tif 